\title{
Emotional behavior in aquatic organisms? Lessons from crayfish and zebrafish
}

\author{
Murilo S. de Abreu ${ }^{1,2}$ (D) | Caio Maximino ${ }^{2,3}$ (D) | Filipe Banha ${ }^{4}$ | \\ Pedro M. Anastácio ${ }^{4}$ (D) | Konstantin A. Demin ${ }^{5,6}$ | \\ Allan V. Kalueff ${ }^{7,8}$ (D) | Marta C. Soares ${ }^{9}$ (D)
}

${ }^{1}$ Bioscience Institute, University of Passo Fundo (UPF), Passo Fundo, Brazil

${ }^{2}$ The International Zebrafish Neuroscience Research Consortium (ZNRC), Slidell, LA, USA

${ }^{3}$ Institute of Health and Biological Studies, Federal University of Southern and Southeastern Pará, Unidade III, Marabá, Brazil

${ }^{4}$ Department of Landscape, Environment and Planning, MARE - Marine and Environmental Sciences Centre, University of Évora, Évora, Portugal

${ }^{5}$ Institute of Experimental

Medicine, Almazov National Medical Research Center, Ministry of Healthcare of Russian Federation, St. Petersburg, Russia

${ }^{6}$ Institute of Translational Biomedicine, St. Petersburg State University, St. Petersburg, Russia

${ }^{7}$ School of Pharmacy, Southwest University, Chongqing, China

${ }^{8}$ Ural Federal University, Ekaterinburg, Russia

${ }^{9} \mathrm{CIBIO}$, Research Centre in Biodiversity and Genetic Resources, University of Porto, Porto, Portugal

\section{Correspondence}

Allan V. Kalueff, PhD., School of Pharmacy, Southwest University, Chongqing, China. Email: avkalueff@gmail.com

Marta C. Soares, CIBIO, Research Centre in Biodiversity and Genetic Resources, University of Porto, Porto, Portugal. Email: marta.soares@cibio.up.pt

\begin{abstract}
Experimental animal models are a valuable tool to study the neurobiology of emotional behavior and mechanisms underlying human affective disorders. Mounting evidence suggests that various aquatic organisms, including both vertebrate (e.g., zebrafish) and invertebrate (e.g., crayfish) species, may be relevant to study animal emotional response and its deficits. Ideally, model organisms of disease should possess considerable genetic and physiological homology to mammals, display robust behavioral and physiological responses to stress, and should be sensitive to a wide range of drugs known to modulate stress and affective behaviors. Here, we summarize recent findings in the field of zebrafish- and crayfish-based tests of stress, anxiety, aggressiveness and social preference, and discuss further perspectives of using these novel model organisms in translational biological psychiatry. Outlining the remaining questions in this field, we also emphasize the need in further development and a wider use of crayfish and zebrafish models to study the pathogenesis of affective disorders.
\end{abstract}

\section{KEYWORDS}

aggressiveness, anxiety, crayfish, social preference, translational research, zebrafish

Murilo S. de Abreu and Caio Maximino shared first authorship.

Edited by Michael Hendricks. Reviewed by Trevor Hamilton and David Baracchi. 


\section{1 | INTRODUCTION}

Proper responses of animals to stress are critical for their survival, however maladaptive responses may also become pathological, resulting in social and affective disorders (Campos, Fogaca, Aguiar, \& Guimaraes, 2013; Nuss, 2015). Animal experimentation has been an indispensable tool for understanding the neurobiological bases of stress and how it connects with emotional responses (Belzung \& Lemoine, 2011; van der Staay, 2006). An emotional response has subjective, behavioral, and physiological components and, while the former is fundamental for human experience, the latter two can be studied in animals (Oatley \& Johnson-Laird, 2014), including both vertebrate and invertebrate species (Baracchi, Lihoreau, \& Giurfa, 2017). Considering that shifts in emotional response are a crucial component of many mental disorders and that the translatability of current studies is still limited, additional and more focused studies are needed to ultimately contribute to understanding these disorders, including widening the spectrum of species used in the central nervous system (CNS) disease modeling (de Mooij-van Malsen, Vinkers, Peterse, Olivier, \& Kas, 2011; Kas et al., 2011; Maximino et al., 2015; Stewart et al., 2015; van der Staay, Nordquist, \& Arndt, 2017). Clearly, the choice of model organisms from other taxa beyond mammals is a challenging task driven by numerous considerations (Maximino et al., 2015). To increase the translatability of such tests, their ethological, ecological and evolutionary aspects must be considered to ensure construct validity (Kas et al., 2011; Maximino, de Brito, Dias, Gouveia, \& Morato, 2010; Maximino \& van der Staay, 2019).

A broader knowledge of behavioral biology of model organisms is critical, and must consider the natural habitat, movement preferences and the overall distribution of organisms in ecological contexts (Benvenuto, Gherardi, \& Ilheu, 2008; Brown, Laundré, \& Gurung, 1999; Ferrari, Sih, \& Chivers, 2009; Laundré, Hernández, \& Ripple, 2010). In rodents, this approach has already been widely used to support the choice of specific behavioral models and tests (Blanchard \& Blanchard, 1988; Hånell \& Marklund, 2014). Complementing rodent models, some aquatic vertebrate (e.g., zebrafish, Danio rerio), and invertebrate (e.g., crayfish) models have recently emerged to improve our understanding of emotional-like states under normal and pathological conditions (Fossat, Bacqué-Cazenave, De Deurwaerdère, Cattaert, \& Delbecque, 2015; Maximino et al., 2015). Studies focusing on these models reveal some comparative relevance to humans (Fossat et al., 2015; Fossat, Bacqué-Cazenave, De Deurwaerdère, Delbecque, \& Cattaert, 2014; Gerlai, 2014; Stewart, Braubach, Spitsbergen, Gerlai, \& Kalueff, 2014), with the advantages of having a shorter generational time that potentially enhances the detection of developmental (e.g., drug/toxin) and transgenerational (e.g., genetic and epigenetic) effects (Imeh-Nathaniel, Orfanakos, Wormack, Huber, \& Nathaniel, 2019; Lakstygal, de Abreu, \& Kalueff, 2018; Scholtz et al., 2003; Spence, Gerlach, Lawrence, \& Smith, 2008). Here, we call for a wider use of aquatic organisms, such as zebrafish and crayfish, for modeling stress, anxiety, aggressiveness and social preference deficits. As we discuss crayfish and

\section{Significance}

Mounting recent evidence suggests that aquatic organisms, including both vertebrate (e.g., zebrafish) and invertebrate (e.g., crayfish) species, may be relevant to studying emotional behavior and its deficits. These model organisms possess considerable genetic and physiological homology to mammals, display robust behavioral and physiological responses to stress, and are sensitive to various drugs known to modulate stress and affective behaviors. Here, we summarize recent findings in the field of zebrafish- and crayfish-based modeling of stress, anxiety, aggressiveness and social preference, and discuss further perspectives of using these novel model organisms in translational biological psychiatry.

zebrafish stress-related behaviors, we also critically evaluate their utility for probing neural underpinnings of anxiety, aggression and social preference.

\section{2 | BEHAVIORAL ECOLOGY OF CRAYFISH AND ZEBRAFISH}

Crayfish include $>540$ Decapoda species belonging to three families (Crandall \& Buhay, 2008)-Astacidae (native to Western North America and Europe), Parastacidae (native to the Southern hemisphere), and Cambaridae (inhabiting the East of the Americas) (Shen, 2008). Found in freshwater environments (e.g., lakes, reservoirs and streams), crayfish tend to burrow or hide under rocks or other shelters to avoid their natural predators (Rhoades, 1962), such as fish, birds and mammals (Delibes \& Adrián, 1987; Holdich, 1988). Generally, crayfish are social animals and form overt social dominance (Figler, Finkelstein, Twum, \& Peeke, 1995; Issa, Adamson, \& Edwards, 1999). Mostly nocturnal and crepuscular species (Holdich, 2001), their locomotion is characterized by short peaks of intense crawling alternated with periods of low mobility (Anastácio et al., 2015; Aquiloni, Ilhéu, \& Gherardi, 2005; Francesca Gherardi \& Barbaresi, 2000; Gherardi, Barbaresi, \& Salvi, 2000). In particular, crayfish (Procambarus clarkii) is an omnivore species that feeds on plant and animal detritus, macrophytes and small live animals (e.g., molluscs, insects, annelids, nematodes, platyhelminthes, tadpoles and fingerlings) (Loureiro, Anastácio, Araujo, Souty-Grosset, \& Almerão, 2015). The genome of this species contains nearly 137 thousand genes and 152 thousand predicted exons, ranging from 150 to 12,807 bp in length (Shi, Yi, \& Li, 2018).

Zebrafish is a small teleost fish species, native to Southeast Asia, that typically inhabits shallow slow-moving streams, small rivers and especially still pools formed during the monsoons (Engeszer, Patterson, Rao, \& Parichy, 2007; Parichy, 2015). Their most common predators include other fishes (e.g., snakeheads [Channa spp.], Indian Leaf fish [Nandus nandus] or freshwater garfish [Xenentodon cancila] [Bass \& Gerlai, 2008; Engeszer, Patterson, et al., 2007]), birds, and 
insects (e.g., dragonfly larvae [Spence et al., 2006]). Zebrafish is a highly social species whose innate shoaling behavior (Engeszer, Da Barbiano, Ryan, \& Parichy, 2007; Engeszer, Patterson, et al., 2007) involves synchronized, ordered group swimming (Delcourt \& Poncin, 2012) that aims to increase the probability of an individual fish detecting/avoiding predators (Pitcher, 1983).

The overlapping ethological and habitat characteristics of these two aquatic species may provide an opportunity to use their natural antipredator and social behaviors (including avoidance, aggression and other conspecific interactions) to develop behavioral assays enabling the study of basic aspects of affective behavior, including anxiety, aggression and sociality. Recognizing the growing value of widening the spectrum of model organisms in translational affective research (Kalueff, Stewart, \& Gerlai, 2014; Stewart, Braubach, Spitsbergen, Gerlai, \& Kalueff, 2014), it is timely to consider using aquatic models, such as crayfish and zebrafish, to examine emotionality-related traits. On the one hand, such use of invertebrate and anamniote model organisms may help bridge important evolutionarily-based gaps in our understanding of the neural underpinnings of normal and pathological behavior (Fossat et al., 2015; Maximino et al., 2015). On the other hand, this approach may also increase the overall translatability of neurobehavioral models, given that mechanisms shared between rodents, zebrafish (Gerlai, 2014; Stewart, Braubach, Spitsbergen, Gerlai, \& Kalueff, 2014) and, possibly, crayfish (Fossat et al., 2014, 2015), are likely to represent "core" pathways shared with humans. Thus, this strategy may further support innovative cross-species modeling (Kas et al., 2011), based on both vertebrate and invertebrate species, for studying basic, evolutionarily conserved, aspects and neural underpinnings of affective behaviors.

\section{3 | MEASURING AFFECTIVE-LIKE BEHAVIOR IN CRAYFISH AND ZEBRAFISH}

\section{1 | Stress/anxiety-like behavior}

Stress-related behavior has been studied in the red swamp crayfish (P. clarkii) (Hobbs, 1972), a native to Mexico and South-Central USA. Since crayfish naturally explore new environments and (like rodents) prefer the dark (Yamane \& Takahata, 2002), their anxiety/avoidancelike behavior can be assessed in the light-dark plus maze consisting of two shaded "dark" and two open "light" arms (Figure 1; BacquéCazenave, Cattaert, Delbecque, \& Fossat, 2017; Fossat et al., 2014, 2015). Stressing crayfish by an electric shock (Fossat et al., 2014, 2015) or descending their social status (Bacqué-Cazenave et al., 2017) increases preference for the dark arms (Table 1). Their sensitivity to benzodiazepines (Bacqué-Cazenave et al., 2017; Fossat et al., 2014) suggests some predictive validity of the model (e.g., similarity of drug effects with clinical treatment in humans) despite major neuroanatomical differences from mammals.

The three most commonly used anxiety tests in zebrafish are the novel tank test (or novel tank diving test, NTT), the open field test (OF), and the light-dark test (LDT) (Figure 1; Kysil et al., 2017). Other anxiety screens include the plus-maze with ramps (Varga et al., 2018; Walsh-Monteiro et al., 2016), the novel object approach (Fior et al., 2018; Johnson \& Hamilton, 2017), and inhibitory avoidance tests (Blank, Guerim, Cordeiro, \& Vianna, 2009; Gorissen et al., 2015; Manuel et al., 2014). Zebrafish NTT is based on geotaxis, an innate escape 'diving' behavior in novel environments, where zebrafish initially spend more time at the bottom and exhibit more erratic movements and freezing/immobility (Bencan, Sledge, \& Levin, 2009; Cachat, Stewart, et al., 2010; Egan et al., 2009). Such natural diving response is generally expected from zebrafish, as in the wild they inhabit shallow pools where their main predators-fish or birds-would attack from the side or the top (Parichy, 2015). However, due to habituation to the NTT apparatus with the lack of overt danger, zebrafish gradually (within minutes) begin to explore the top area (Stewart et al., 2013; Wong et al., 2010). A typical NTT represents a transparent narrow rectangular tank virtually divided into two (top and bottom) or three areas (bottom, middle, and top) (Egan et al., 2009; Kysil et al., 2017). This test assesses three major phenotypic domains: exploration of novel environments (time spent in the upper/ bottom zone, latency to enter the top, number of crossings between the zones), fear-like behavior (e.g., freezing and erratic swimming), and overall activity/locomotion (e.g., distance traveled and velocity; Cachat, Stewart, et al., 2010).

Like in rodents, zebrafish NTT behaviors can be explained by a classical motivational conflict theory (Montgomery, 1955) based on a balance between anticipation of potential threats versus exploration (Davis, Walker, \& Lee, 1997; Maier, 1993) and also by the avoidance theory viewing animal novelty-evoked behavior as driven by avoidance responses (e.g., avoiding potentially dangerous areas) (Gallup, 1974, 1979; Wallnau \& Gallup, 1977). Finally, while rodent studies suggest that neural circuits of fear may differ from those involved in anxiety (Davis et al., 1997), this distinction remains unclear in fish models. However, as NTT responses are highly sensitive to anti-anxiety drugs (Stewart, Wu, et al., 2011), this suggests a reasonable predictive validity in this assay.

The OF is another popular test to assess animal affective-like behavior. In rodents, the OF apparatus typically consists of a circular or rectangular arena (Denenberg, 1969; Harro, 2018) to measure locomotion (e.g., the number of squares crossed or total distance traveled) and anxiety-like center avoidance (e.g., entries or time spent in center vs. periphery). Stressed/anxious animals decrease the exploration and increase time spent in the periphery of the apparatus (thigmotaxis) (Denenberg, 1969; Harro, 2018). Similar to rodents, both larvae and adult zebrafish display characteristic patterns of exploration, with prominent thigmotaxis (Ahmad \& Richardson, 2013; Stewart, Gaikwad, Kyzar, \& Kalueff, 2012), suggesting that spatiotemporal strategies of exploration may be evolutionarily conserved across vertebrate species (Stewart et al., 2012).

The zebrafish LDT is based on the natural tendency of fish to display scototaxis, avoiding brightly lit areas and spending more time in the dark to minimize their detection by predators (Maximino, De Brito, de Mattos Dias, Gouveia, \& Morato, 2010; Serra, Medalha, \& Mattioli, 1999). The typical LDT apparatus is a rectangular tank consisting of two equal vertical portions, black and white (Maximino, 

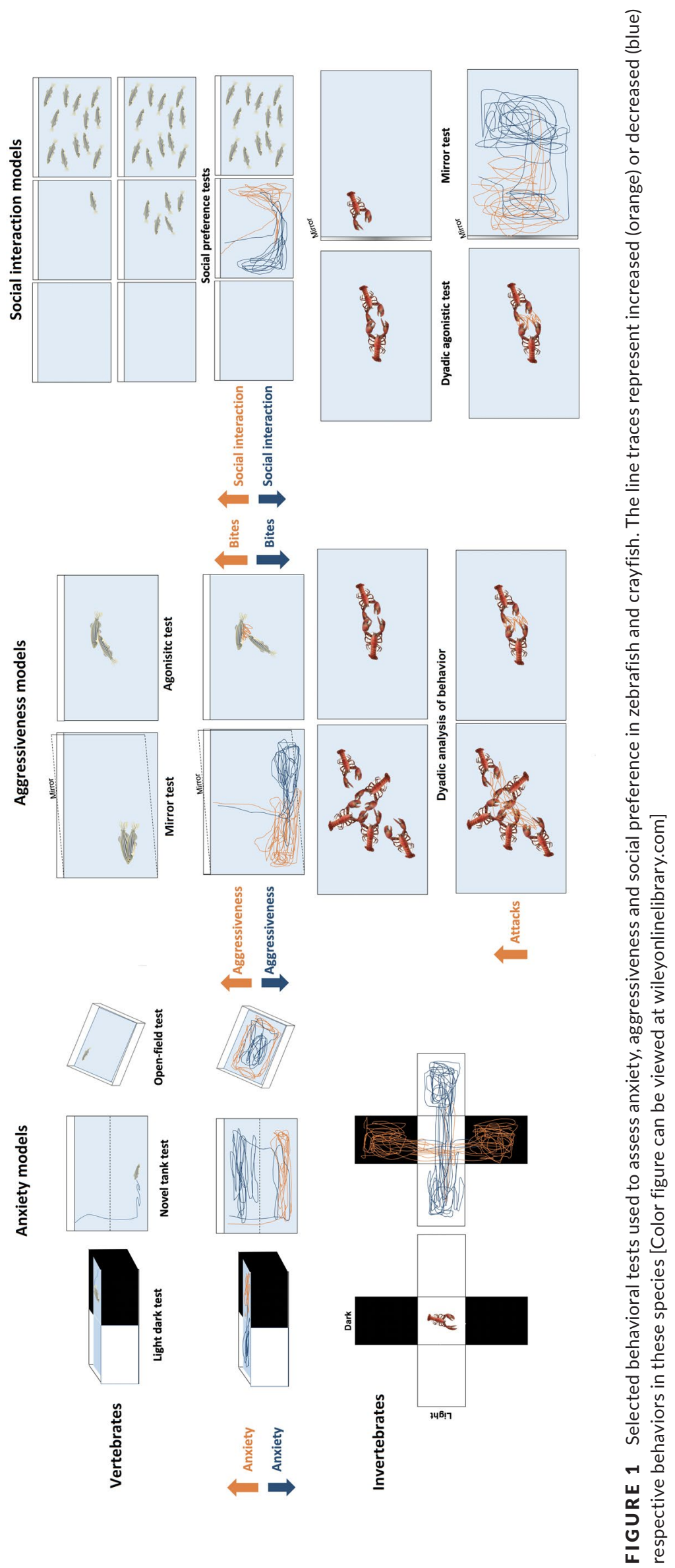
TABLE 1 Selected examples of pharmacological modulation of crayfish behavior

\begin{tabular}{|c|c|c|c|}
\hline Drugs & Dose & Behavioral effects & References \\
\hline $\begin{array}{l}\text { 5-Hydroxytryptophan (5- } \\
\text { HTP) and fluoxetine }\end{array}$ & $\begin{array}{r}100 \mathrm{mg} / \mathrm{kg} 5-\mathrm{HTP}, \text { or } 100 \mathrm{mg} / \mathrm{kg} \\
5-\mathrm{HTP}+0.31 \mathrm{mg} / \mathrm{kg} \text { fluoxetine }\end{array}$ & $\begin{array}{l}\text { Increased aggression in } 5 \text {-HTP versus } \\
5-\mathrm{HTP}+\text { fluoxetine subordinates }\end{array}$ & $\begin{array}{l}\text { Dingman, Hurlburt, and } \\
\text { Otte (2009) }\end{array}$ \\
\hline $\begin{array}{l}\text { Crustacean hyperglycemic } \\
\text { hormone }(\mathrm{cHH})\end{array}$ & $0.5 \mu \mathrm{g}$ per crayfish & Increased individual aggression & $\begin{array}{l}\text { Aquiloni, Panksepp, and } \\
\text { Huber (2012) }\end{array}$ \\
\hline \multicolumn{4}{|l|}{ Anxiety } \\
\hline Serotonin $(5-\mathrm{HT})$ & $5 \mu \mathrm{g} / \mathrm{g}$ & Anxiogenic effect & Fossat et al. (2015) \\
\hline Mianserin and methysergide ${ }^{a}$ & $1 \mathrm{nmol} / \mathrm{g}$ & Reduced anxiogenic effects of $5-\mathrm{HT}$ & Fossat et al. (2015) \\
\hline D-amphetamine & 1 and $5 \mathrm{mg} / \mathrm{kg}$ & $\begin{array}{l}\text { Increased exploration (e.g., antennal move- } \\
\text { ments, rearing, and locomotion) }\end{array}$ & Alcaro et al. (2011) \\
\hline Scopolamine & $100 \mathrm{ng} / \mathrm{g}$ & $\begin{array}{l}\text { Increased agonistic behavior in the dyadic } \\
\text { test }\end{array}$ & $\begin{array}{l}\text { Jiménez-Morales et al. } \\
\text { (2018) }\end{array}$ \\
\hline
\end{tabular}

a Mianserin is a serotonin 5-HT2 receptor blocker, and methysergide is a 5-HT1/2 receptor blocker.

De Brito, et al., 2010). In this test, anxiogenic-like effects include more time spent in the dark (Maximino, De Brito, et al., 2010), in addition to risk assessment (defined as partial or very fast entries in the white compartment, during which the animal gathers information on threat levels), thigmotaxis (swimming near the walls of the tank), freezing (cessation of swimming and most movements), and erratic swimming (a zig-zagging, fast pattern of swimming in which the animal's direction is unpredictable to predators) in the white area (Araujo et al., 2012). Interestingly, the characterization of anxiety in the LDT paradigm is age-specific, as for instance, larval fish display natural dark avoidance (Steenbergen, Richardson, \& Champagne, 2011) that is attenuated by anxiolytic (e.g., diazepam, buspirone or ethanol) and increased by anxiogenic (e.g., caffeine) drugs (Steenbergen et al., 2011). Such dark avoidance behaviors have also been demonstrated in other fish species, including mosquitofish (Gambusia holbrooki; Maximino, Marques de Brito, Dias, Gouveia, \& Morato, 2010). The sensitivity of zebrafish models to anxiotropic drugs (Maximino, da Silva, et al., 2014) suggests their reasonable predictive value, implicating both crayfish and zebrafish as potential models for anxiety-like states and the optimization of CNS drug screening.

\subsection{Aggression}

Aggression has long been studied in aquatic invertebrates (Bovbjerg, 1956; Dingman et al., 2009; Sato \& Nagayama, 2012; Tierney, Greenlaw, Dams-O'Connor, Aig, \& Perna, 2004). In crayfish, aggressive and social behaviors are usually assessed during dyadic agonistic encounters, often with overt dominance-subordinated relationships (Bovbjerg, 1956; Dingman et al., 2009; Issa et al., 1999; Moore, 2007; Sato \& Nagayama, 2012; Tierney et al., 2004).
Behavioral endpoints in this test vary from low-stress (decreased approaches to a potential opponent) to high-stress (unrestrained fighting with attempts to remove the chelae or legs of the opponent) (Huber \& Delago, 1998). Fighting usually stops when one individual retreats (using a tail flip) or crawls away from the opponent (Bruski \& Dunham, 1987).

In zebrafish, multiple paradigms have been used to elicit and assess aggressive behavior (de Abreu et al., 2019; Zabegalov et al., 2019). For example, a widely used assay is the mirror test (Barbosa, Lima-Maximino, \& Maximino, 2019; Gerlai, Lahav, Guo, \& Rosenthal, 2000; Giacomini et al., 2016), where aggressive behavior is evoked by presenting fish with a mirror, typically placed on one side of the tank at an angle (Figure 1). The interaction of the fish with its own image is recorded after a short acclimatization period (Norton et al., 2011). To score aggression, the tank can be virtually divided into equal segments, and time spent near the mirror, as well as time spent in aggressive display, is assessed as an index of aggressive motivation (Way, Ruhl, Snekser, Kiesel, \& McRobert, 2015). Displays are usually scored as the fish erecting its dorsal and anal fins and flaring its body flank toward the opponent. It is also possible to elicit aggressive displays by showing videos of conspecifics, evaluating aggressive behaviors (e.g., bites) and time spent in the area near the video stimulus (de Abreu et al., 2019; Way et al., 2015; Zabegalov et al., 2019). Although both models elicit aggressive displays in zebrafish, because the animal is unable to interact with the opponent, such aggressive behavior does not follow the usual escalation observed in natural contexts. Thus, interactions with conspecifics (e.g., dyadic fights between size-matched males) to elicit the complete aggressive repertoire from both appetitive (display) to consummatory (fight) components (Dahlbom, Backström, Lundstedt-Enkel, \& Winberg, 2012; 
Oliveira, Silva, \& Simões, 2011; Teles \& Oliveira, 2016), become necessary .

In dyadic behavioral assays, same-sex pairs of fish are typically placed into a tank, isolated by a removable opaque divider. After an overnight acclimation, the divider is removed, and the fish are left to interact for $30 \mathrm{~min}$, which is usually sufficient to determine a clear winner. Behavioral patterns that can be observed include displays; circling (fish approach one another in opposite directions and with erected fins, and in an antiparallel position circle around each other usually ascending in the water column); strikes (fish swims rapidly toward the opponent but no physical contact occurs between them); bites (fish opens and closes its mouth in contact with the body surface of the opponent); chases (similar to strike behavior but with an active pursuit by the aggressor); retreats (fish swims rapidly away from the opponent in response to a strike or a bite); escapes (continued escape reaction in response to a chase); and freezing (fish stays immobile with all fins retracted) (de Abreu et al., 2019; Oliveira, Silva, \& Simoes, 2011; Zabegalov et al., 2019).

\section{3 | Sociality}

The social domain has also been studied in aquatic invertebrates (Bovbjerg, 1956; Dingman et al., 2009; Sato \& Nagayama, 2012; Tierney et al., 2004). Social interactions in crayfish are usually measured during dyadic agonistic encounters, sometimes during the establishment of dominance-subordinated relationships (Hayes, 1975; Huber \& Delago, 1998). The mirror test has also been used to evaluate social response, in which an adult crayfish is placed inside a glass tank with a mirror, assessing rearing up (climbing the wall), turning, cornering (facing the corner for $>5 \mathrm{~s}$ ), backward walking, and crossing the midline of the aquarium (Drozdz, Viscek, Brudzynski, \& Mercier, 2006). Crayfish behavioral responses seem to depend on prior socialization levels (Drozdz et al., 2006). Indeed, crayfish that had previously been housed in isolation show no difference in rearing, turning, cornering, or backward walking between the mirror and non-mirror portions of the tank (Drozdz et al., 2006). In contrast, crayfish housed in pairs increase all five behaviors in front of the mirrors (vs. in the nonmirror portions of the tank) and spend more time near the mirror (Drozdz et al., 2006), similarly to zebrafish, whose social isolation typically decreases shoal cohesion, likely due to the absence of social cues (Shams, Amlani, Buske, Chatterjee, \& Gerlai, 2018). Together, these findings suggest that crayfish may as well be a suitable model organism for further social testing.

Several tests are widely used to assess social/agonistic behavior in zebrafish beyond aggression (Barba-Escobedo \& Gould, 2012; Engeszer, Ryan, \& Parichy, 2004; Gerlai et al., 2000; Muto, Taylor, Suzawa, Korenbrot, \& Baier, 2013). For example, zebrafish social preference can be tested in a tank positioned between two other tanks, one empty and another containing a single conspecific (BarbaEscobedo \& Gould, 2012) or a group of zebrafish (Giacomini et al., 2016). Fish are acclimated to the tank before behavior is recorded, and the videos are then analyzed, assessing time spent in proximity to the conspecifics (Barba-Escobedo \& Gould, 2012; Giacomini et al., 2016). The shoaling test has also been used to assess sociality in fish (Miller \& Gerlai, 2007, 2011). In this test, animals are analyzed in groups, assessing inter-fish distance, nearest and/or farthest neighbor distance, and/or shoal area (Green et al., 2012; Miller \& Gerlai, 2007). However, this test does not strictly measure social preference per se, and is sensitive to changes in other behavioral domains (e.g., anxiety-like behavior), since, for example, anxiety naturally increases shoal cohesion in zebrafish (Engeszer et al., 2004; Miller \& Gerlai, 2007).

\subsection{Neural mechanisms in stress and affective behaviors}

In crayfish, stress-related behavior has been linked to altered serotonin signaling (Fossat et al., 2014). For example, stressing crayfish via electric shocks (Fossat et al., 2014, 2015) or by lowering their social status (Bacqué-Cazenave et al., 2017), seems to increase anxiety-like behaviors, an effect that is mimicked by injecting serotonin into crayfish hemolymph (Fossat et al., 2014; Table 1). Serotonin also triggers crayfish aggression (Tierney et al., 2004), possibly by reducing the likelihood of retreating and by increasing fight duration (Huber \& Delago, 1998), thus, evoking a pro-aggressive and anxiogenic profile. Crayfish social status is usually established in dyadic fights (winner vs. loser) with physically larger animals more likely to become winners, however, when injected with serotonin, smaller crayfish are successfully able to win these confrontations against larger untreated crayfish (Momohara, Kanai, \& Nagayama, 2013). Moreover, larger crayfish injected with octopamine also lose when set against untreated smaller animals, while wining by dominant crayfish is prevented by mianserin, an antagonist of serotonin receptors, and reinforced by fluoxetine (Momohara et al., 2013). However, current knowledge of socio-positive behaviors and their modulation by the serotoninergic system in crayfish is still limited, meriting further studies.

Analyses of zebrafish anxiety-like (Egan et al., 2009; Maximino \& Herculano, 2010), aggressive (Norton \& Bally-Cuif, 2012; Zabegalov et al., 2019) and social behaviors (Soares, Cardoso, Carvalho, \& Maximino, 2018) strongly implicate the serotonergic system is modulating fish affective behaviors (Table 2). This system is particularly relevant, because albeit not fully conserved in terms of neuroanatomy and genetics (Herculano \& Maximino, 2014), it is functionally associated with emotional domains across vertebrates and invertebrates (Curran \& Chalasani, 2012; Herculano \& Maximino, 2014; Mohammad et al., 2016). Zebrafish anxiety-like behavior is usually affected by serotonin in a receptor-dependent manner (Herculano \& Maximino, 2014; Maximino, Lima, Costa, Guedes, \& Herculano, 2014; Nowicki, Tran, Muraleetharan, Markovic, \& Gerlai, 2014; Ogawa, Ng, Ramadasan, Nathan, \& Parhar, 2012; Ponzoni, Daniela, \& Sala, 2016). For example, serotonergic psychedelics, such as lysergic acid diethylamide (LSD) (Grossman et al., 2010), mescaline (Kyzar et al., 2012) and 3,4-methylenedioxymethamphetamine (MDMA; 
TABLE 2 Selected examples of pharmacological modulation of zebrafish behavior

\begin{tabular}{|c|c|c|c|}
\hline Drugs & Dose & Behavioral effects & References \\
\hline Dizocilpine (MK-801) & $5 \mu \mathrm{M}$ & Reduced aggression & Zimmermann, Gaspary, Siebel, and Bonan (2016) \\
\hline Fluoxetine & $50 \mu \mathrm{g} / \mathrm{L}$ & Reduced aggression & Giacomini et al. (2016) \\
\hline \multicolumn{4}{|l|}{ Anxiety } \\
\hline O-Acetyl-L-carnitine & $0.1,1$ and $10 \mathrm{mg} / \mathrm{L}$ & Anxiolytic effect & Pancotto, Mocelin, Marcon, Herrmann, and Piato (2018) \\
\hline Amitriptyline & $50 \mu \mathrm{g} / \mathrm{L}$ & Anxiolytic effect & Meshalkina et al. (2018) \\
\hline Fluoxetine & $0.1 \mathrm{mg} / \mathrm{L}$ & $\begin{array}{l}\text { Reverted effects of unpredictable } \\
\text { chronic stress (UCS) }\end{array}$ & Song et al. (2018) \\
\hline $\mathrm{N}$-acetylcysteine & $1 \mathrm{mg} / \mathrm{L}$ & Reverted effects of UCS & Mocelin et al. (2019) \\
\hline Ibogaine & 10 and $20 \mathrm{mg} / \mathrm{L}$ & Anxiolytic effect & Cachat et al. (2013) \\
\hline Noribogaine & 1,5 and $10 \mathrm{mg} / \mathrm{L}$ & Anxiolytic effect & Kalueff, Kaluyeva, and Maillet (2017) \\
\hline Scopolamine & $120 \mathrm{mg} / \mathrm{L}$ & Anxiogenic effect & Volgin, Yakovlev, Demin, Alekseeva, and Kalueff (2019) \\
\hline Lithium carbonade & $100 \mathrm{mg} / \mathrm{L}$ & Anxiogenic effect & Zanandrea, Abreu, Piato, Barcellos, and Giacomini (2018) \\
\hline Caffeine & $100 \mathrm{mg} / \mathrm{L}$ & Anxiogenic effect & Egan et al. (2009) \\
\hline \multicolumn{4}{|l|}{ Social preference } \\
\hline Alcohol & $0.25,0.75$ and $1 \%$ & Disrupted group cohesion & Miller, Greene, Dydinski, and Gerlai (2013) \\
\hline Diazepam & $16 \mu \mathrm{g} / \mathrm{L}$ & Decreased social interaction & Giacomini et al. (2016) \\
\hline MK-801 & $5 \mu \mathrm{M}$ & Lower social interaction & Seibt et al. (2011) \\
\hline Nicotine & 4 and $8 \mathrm{mg} / \mathrm{L}$ & Disrupted group cohesion & Miller et al. (2013) \\
\hline Proline & $1.5 \mathrm{mM}$ & Disrupted group cohesion & Savio, Vuaden, Piato, Bonan, and Wyse (2012) \\
\hline
\end{tabular}

Abbreviations: LSD, lysergic acid diethylamide; MDMA, 3,4-methylenedioxymethamphetamine.

Stewart, Riehl, et al., 2011), evoke anxiolytic-like effects in zebrafish, increasing top swimming in the NTT and decreasing dark preference in the LDT. Serotonin also lowers aggressive behavior (Barbosa et al., 2019; Norton et al., 2011) and increases social preference in zebrafish (Barba-Escobedo \& Gould, 2012; Ponzoni, Sala, \& Braida, 2016).

Importantly, distinct behavioral and molecular effects can be triggered by both acute (Abreu et al., 2015; Barbosa et al., 2019; de Abreu et al., 2014; Giacomini et al., 2016) and chronic (Egan et al., 2009; Marcon et al., 2016; Petrunich-Rutherford, 2019; Song et al., 2018) exposure to serotonergic drugs, suggesting pro-social, anti-aggressive and anxiotropic roles of serotonin in zebrafish. In rodents, the serotonergic system also modulates anxiety (Broekkamp, Berendsen, Jenck, \& Van Delft, 1989; Griebel, 1995; Sánchez \& Meier, 1997), aggression (Chiavegatto et al., 2001; Ferrari, Palanza, Parmigiani, de Almeida, \& Miczek, 2005; Olivier \& Mos, 1992) and social behaviors (Dekeyne, Denorme, Monneyron, \& Millan, 2000; Gemmel et al., 2017). For example, like zebrafish (Egan et al., 2009), rats chronically treated with fluoxetine display anxiolytic-like behavior and reduced behavioral responses to stress (e.g., reverting the suppression of exploration induced by stress; Zhang et al., 2000). In addition, 5-HT1A receptor agonists buspirone, ipsapirone and 8$\mathrm{OH}$-DPAT reduce aggression (Olivier \& Mos, 1992) and a selective serotonin reuptake inhibitor (SSRI) citalopram impairs social interaction in rodents (Dekeyne et al., 2000). Therefore, zebrafish and rodents present rather similar effects of serotoninergic modulation of emotional behaviors.

While we mostly focus here on serotonin as a well-studied brain neurotransmitter involved in behavioral modulation in multiple species, other neurotransmitter systems that regulate affective behaviors in various species involve the noradrenergic, dopaminergic and gamma 
aminobutyric acid (GABA)-ergic systems. For example, exposure to chlordiazepoxide, a GABA-ergic benzodiazepine ligand, reverts anxiety-like behavior in crayfish caused by stress (crayfish submitted to varying electric fields; Fossat et al., 2014) independently of changes in monoamine levels (Fossat et al., 2015). Crayfish exposed to $434 \mathrm{mM}$ ethanol show hyperactivity (Blundon \& Bittner, 1992), whereas injection of dopamine increases crayfish swimmeret beating (Tierney, Kim, \& Abrams, 2003). Furthermore, aggressive behaviors in crustaceans involve motivation to engage in fighting, with winners presenting higher blood levels of dopamine and serotonin than losers (Sneddon, Taylor, Huntingford, \& Watson, 2000).

Interestingly, the use of crayfish model systems has also demonstrated some promise in the study of the biological mechanisms of addiction (Alcaro et al., 2011) which are strongly implicated in behavioural deficits and stress (Sinha, 2008; Torres-Berrio, Cuesta,

TAB LE 3 Selected open questions relevant to modeling affective and social disorders in vertebrates and invertebrates

\section{Questions}

How to develop crayfish and zebrafish assays that are most robust to study emotional disorders?

Are there individual differences in emotional behavior of both crayfish and zebrafish?

How does crayfish and zebrafish 'personality' contribute to the expression of emotional phenotypes?

Do emotional behaviors differ in both zebrafish and crayfish in strain- and sex-specific manner?

What is the role of epigenetic modulation of crayfish and zebrafish emotional deficits?

Are there structures in the zebrafish and the crayfish nervous systems that participate in the development of emotional deficits but do not have close analogues in humans?

How relevant are the existing behavioral assays in crayfish and zebrafish to mimick human emotional disorders?

Are there significant differences in traditional drugs' effects between crayfish, zebrafish and humans?

How can we objectively link quantitative characteristics of zebrafish and crayfish behavior to symptoms of human emotional disorders?

Is there any difference in emotional phenotypes presented by zebrafish and crayfish in natural habitat versus laboratory environment?

How can stress affect (or trigger) emotional phenotypes in crayfish and zebrafish?

How to develop crayfish and zebrafish models of emotional disorders that display sex differences in pathogenesis similar to those in humans?

Can computer technologies (e.g., behavioral visualization software) lead to automatic recognition and extraction of crayfish and zebrafish emotional behaviors?

Can current genetic tools (e.g., CRISPR) assist in the understanding of the mechanisms of emotional disorders in these two aquatic species?

What is the impact of gut microbiota on models of emotional disorders in crayfish and zebrafish?
Lopez-Guzman, \& Nava-Mesa, 2018). Indeed, crayfish exposure to cocaine, morphine and methamphetamine increases mobility (ImehNathaniel et al., 2017), whereas exposure to D-amphetamine stimulates exploration (Alcaro et al., 2011). Finally, exposure of crayfish to morphine increases locomotor activity acutely but reduces it at higher and/or chronic doses (Dziopa et al., 2011).

Like crayfish, zebrafish are also highly sensitive to pharmacological modulation, with significant impact on anxiety-like behavior. For example, zebrafish also increase locomotor activity following D-amphetamine exposure (Irons, MacPhail, Hunter, \& Padilla, 2010). They demonstrate anxiolytic effects following a 1-week ethanol treatment, increasing exploration and reducing erratic swimming (Egan et al., 2009). In moderate doses, alcohol enhances aggression and preference for conspecifics, whereas its high concentrations impairs these responses (Gerlai et al., 2000). Discontinuation of ethanol and morphine evokes anxiogeniclike behavior and elevated whole-body cortisol in zebrafish (Cachat, Canavello, et al., 2010). Such drug responses may also be influenced by sex, since cocaine withdrawal-evoked anxiogenic-like behavior develops earlier in female zebrafish, but is more robust and persistent in males (Patiño, Yu, Yamamoto, \& Zhdanova, 2008).

Exposure to dexmedetomidine, an alpha-2 adrenergic receptor agonist, causes sedation in zebrafish (Ruuskanen, Peitsaro, Kaslin, Panula, \& Scheinin, 2005), as do common GABA-ergic sedatives diazepam and barbiturates (Zhdanova, Wang, Leclair, \& Danilova, 2001). In contrast, anxiogenic GABA-lytic drugs, such as ionophore channel blockers pentylenetetrazole and picrotoxin (Wong et al., 2010), or an inverse benzodiazepine agonist FG-7142 (López-Patiño, Yu, Cabral, \& Zhdanova, 2008), predictably evoke anxiety-like behavior in zebrafish, paralleling their well-studied behavioral effects in rodents and humans.

Stress itself further modulates crayfish and zebrafish emotional responses. For example, zebrafish exposed to unpredictable chronic stress (UCS) increase aggressive response, whole-body cortisol levels (Rambo et al., 2017) and anxiety-like behavior (Marcon et al., 2016; Song et al., 2018). Acute stress elevates zebrafish aggressive and anxiety-like behavior, while decreasing social interaction (Cachat, Stewart, et al., 2010; Giacomini et al., 2016). In crayfish, acute stress also increases anxiety-like behaviors (Fossat et al., 2014, 2015). In turn, such evoked anxiety can be rescued by anxiolytic, antidepressant and antipsychotic drugs (e.g., benzodiazepines, SSRI, risperidone) (Fossat et al., 2014; Giacomini et al., 2016; Idalencio et al., 2015; Marcon et al., 2015, 2016).

\section{ECOLOGICAL IMPLICATIONS OF CRAYFISH AND ZEBRAFISH MODELS: FUTURE DIRECTIONS}

As a model species, zebrafish is characterized by easy laboratory maintenance, short generation times, well-described genetics (Detrich lii, Westerfield, \& Zon, 1998) and detailed behavioral ethograms (Kalueff et al., 2013). Zebrafish mature at about 3 months in laboratory conditions (Eaton \& Farley, 1974). Females can spawn every 1-6 days and a single clutch may contain several hundred eggs (Spence \& Smith, 
2006). Generation time is short, typically $3-4$ months, and development is rapid, with larvae displaying food seeking and active avoidance behaviors within five days post fertilization, i.e. 2-3 days after hatching (Kimmel, Ballard, Kimmel, Ullmann, \& Schilling, 1995). Mean life span of domesticated zebrafish is about 42 months, with the oldest individual surviving for 66 months (Gerhard et al., 2002). In the wild, individuals normally only live for one year (Spence, Fatema, Ellis, Ahmed, \& Smith, 2007). There are also some key ecological implications in their behavioral output. For instance, zebrafish habitat includes shallow, slow-moving water with mud, sand/gravel, aquatic vegetation, and shelters from overhanging vegetation and/or banks (Parichy, 2015). The presence of vegetation has been associated with increased aggression in zebrafish in population-dependent manner (Bhat, Greulich, \& Martins, 2015). For example, differences in feeding after disturbance have been observed between wild-derived and laboratory-reared zebrafish populations (Bhat et al., 2015).

From the ecological point of view, red-swamp crayfish has some added practical advantages (compared to zebrafish), including higher resistance to experimental manipulations and handling due to their larger size and hard exoskeleton. However, they also present some husbandry problems, such as considerable cannibalism in captivity (Stein, 1977) and higher aggression (versus other freshwater crayfish (Gherardi, 2013; Reynolds, 2011), thereby complicating their manipulation and laboratory use. Another advantage of using crayfish is the possibility of longer-term manipulation out of water, since this species is extremely resistant (physiologically and behaviorally) to air exposure stress (Banha \& Anastácio, 2014; Ramalho \& Anastácio, 2015). Although zebrafish are capable of surviving in hypoxic conditions (Rees, Sudradjat, \& Love, 2001), low environmental oxygen concentrations can produce robust behavioral, physiological or biochemical deficits (Jensen, Nikinmaa, \& Weber, 1993; Kramer, 1987; Kramer \& Mehegan, 1981). Under ideal conditions the time to maturation in red-swamp-crayfish is 2 months and its generation time is 4.5 months (Huner, Barr, \& Coleman, 1991). In the wild, their life span is up to 1.5 years but, in the laboratory, crayfish can live for 3-6 years (Huner et al., 1991). Depending on their size, females usually lay 100-500 eggs in each clutch and can reproduce more than once a year (Huner et al., 1991). Thus, crayfish arise as an important model for experimental studies due to their easy laboratory maintenance and high reproductive capacity.

Individual identification and labeling in the red-swamp crayfish is easier than in zebrafish, including subcutaneous injection of color dyes (Cheung, Chatterjee, \& Gerlai, 2014), acoustic (PIT) tags (Cousin et al., 2012; Delcourt et al., 2018), binary-coded wire tags (Isely \& Eversole, 1998), enumerated plastic streamers (Meriweather, 1986), oil-based permanent markers (Ramalho, McClain, \& Anastácio, 2010) and cauterization applied to exoskeleton (Buřič, Kozák, \& Vích, 2008). For a longer-term marking, implanting alphanumeric tag or visible implant elastomers (both applied under transparent ventral abdominal cuticle) or internal PIT tags (Buřič et al., 2008) have already been used, therefore making behavioral research of individual characteristic easier in this species.

Furthermore, somewhat differing from zebrafish, red-swamp crayfish have a remarkable tolerance to a wide array of ecological conditions (Huner et al., 1991), making them ideal for laboratory use. However, from the bioenvironmental perspective, some risks include escape and invasion of natural habitats, whose strong impacts have led to the inclusion of this species in several restrictive national or international legislations (Capinha, Leung, \& Anastácio, 2011; Lodge et al., 2012; Souty-Grosset et al., 2016). Another ecological risk is the transmission of diseases or parasites to wild animals, even if the species itself does not escape the laboratory. The red swamp crayfish and other North American crayfish species carry the crayfish plague, a deadly disease whose transmission to wild populations of crustaceans is a serious concern (Svoboda, Mrugała, Kozubíková-Balcarová, \& Petrusek, 2017). Finally, while other common crayfish species may represent potential candidates for laboratory use, they also pose higher ecological risks than the red-swamp crayfish. For example, Procambarus fallax, $f$. virginalis is a parthenogenetic (Martin, Dorn, Kawai, van der Heiden, \& Scholtz, 2010), highly invasive crayfish (Chucholl, Morawetz, \& Groß, 2012).

\section{5 | CONCLUSION}

In summary, studying affective behavior in both invertebrate (crayfish) and vertebrate (zebrafish) aquatic models may provide important insights into emotional responses and mechanisms underlying human affective illnesses, also fostering the discovery of novel drugs to treat these disorders (see Table 3). These animal models may also become important tools in the studies of emotional disorders due to their generally conserved genetic homology to mammals (Gutekunst et al., 2018; Howe et al., 2013; Shi et al., 2018). For example, crayfish-due to the underlying mechanisms which are strongly conserved-have recently emerged as a promising novel model organism in addiction research, showing sensitivity to human drugs of abuse (e.g., cocaine and amphetamine) in the conditioned place preference paradigm (Huber, Panksepp, Nathaniel, Alcaro, \& Panksepp, 2011). Likewise, zebrafish have also been used to study addiction (Mathur \& Guo, 2010; Schneider, 2017). For example, larvae pretreated with morphine prefer water containing morphine in a self-immersion test (Bretaud et al., 2007). Another key practical advantage of utilizing aquatic models, such as zebrafish and crayfish, is the use of immersion as route of administration, which remarkably facilitates low-invasive treatment, group medication (Treves \& Brown, 2000) and increases the ease of drug dosing (Schroeder \& Sneddon, 2017). Therefore, zebrafish and crayfish may also represent useful model organisms for bioethical research, utilizing less stressful and non-invasive procedures (de Abreu, Giacomini, Echevarria, \& Kalueff, 2019).

In general, to better understand human emotional disorders, we may need to target not only specific individual phenotypes of interest, but also their neural aspects, such as neurochemistry or circuitry (Demin et al., 2019). Because no animal is a perfect replication of the human emotional landscape, not all criteria can be met by a single model of affective behavior (Demin et al., 2019). Thus, using a combination of different model organisms (e.g., rodents, zebrafish and crayfish) may improve our understanding of each specific emotional condition.

Despite all the advantages, these two aquatic models also present some limitations. For example, there are some discrepancies in 
pharmacological effects on emotional behaviors, including anxiolytic (Hamilton et al., 2017), anxiogenic-like (de Abreu, Friend, Amstislavskaya, \& Kalueff, 2018) or no effects (Cho, Lee, Choi, Hwang, \& Lee, 2012) of scopolamine in zebrafish. In contrast, the effects of scopolamine on anxiety in crayfish are unknown. Serotonin exerts both anxiogenic- and anxiolytic-like effect in crayfish (Fossat et al., 2015; Trevor James Hamilton, Kwan, Gallup, \& Tresguerres, 2016), while in rodents and zebrafish it has an anxiolytic-like action (Farhan \& Haleem, 2016; Giacomini et al., 2016). One possible explanation for these differences may be genetic differences from mammals, including some duplicated genes (in zebrafish), so the combination of genetic components and the expression of these genes may result in distinct phenotypic responses, and may explain some of the varying responses to drugs when compared to humans and rodents (Gutekunst et al., 2018; Kalueff et al., 2014). Taken together, the evidence discussed here suggests both zebrafish and crayfish as promising experimental models of stress-related conditions, including anxiety, aggression and social deficits.

\section{ACKNOWLEDGMENTS}

MCS is currently supported by National Funds through FCT Foundation for Science and Technology. AVK is supported by the Russian Science Foundation grant 19-15-00053. KAD is supported by the Fellowship of the President of Russia and SPSU Rector Productivity Fellowship for PhD Students. CM is supported by CNPq/Brazil under Edital Universal 2016 (400726/2016-5). PMA and FB are supported by the strategic plan of MARE - Marine and Environmental Sciences Centre (UID/MAR/04292/2019).

\section{CONFLICT OF INTEREST}

Authors declare no conflict of interest.

\section{AUTHOR CONTRIBUTIONS}

Conceptualization, M.S.A., M.C.S., C.M. and A.V.K.; Writing - Original Draft, M.S.A., C.M., F.B., P.M.A., K.A.D., A.V.K. and M.C.S.

\section{ORCID}

Murilo S. de Abreu (iD https://orcid.org/0000-0001-5562-0715

Caio Maximino (iD https://orcid.org/0000-0002-3261-9196

Pedro M. Anastácio iD https://orcid.org/0000-0003-1808-3847

Allan V. Kalueff iD https://orcid.org/0000-0002-7525-1950

Marta C. Soares (iD https://orcid.org/0000-0002-5213-2377

\section{REFERENCES}

Abreu, M. S., Giacomini, A. C. V., Koakoski, G., Oliveira, T. A., Gusso, D., Baldisserotto, B., \& Barcellos, L. J. G. (2015). Effects of waterborne fluoxetine on stress response and osmoregulation in zebrafish. Environmental Toxicology and Pharmacology, 40(3), 704-707. https://doi.org/10.1016/j.etap.2015.09.001
Abreu, M. S. D., Koakoski, G., Ferreira, D., Oliveira, T. A., Rosa, J. G. S. D., Gusso, D., ... Barcellos, L. J. G. (2014). Diazepam and fluoxetine decrease the stress response in zebrafish. PLoS ONE, 9(7), 5. https://doi.org/10.1371/journal.pone.0103232

Ahmad, F., \& Richardson, M. K. (2013). Exploratory behaviour in the open field test adapted for larval zebrafish: Impact of environmental complexity. Behavioural Processes, 92, 88-98. https://doi.org/10.1016/j. beproc.2012.10.014

Alcaro, A., Panksepp, J., \& Huber, R. (2011). D-amphetamine stimulates unconditioned exploration/approach behaviors in crayfish: Towards a conserved evolutionary function of ancestral drug reward. Pharmacology Biochemistry and Behavior, 99(1), 75-80. https://doi. org/10.1016/j.pbb.2011.04.004

Anastácio, P. M., Banha, F., Capinha, C., Bernardo, J. M., Costa, A. M., Teixeira, A., \& Bruxelas, S. (2015). Indicators of movement and space use for two co-occurring invasive crayfish species. Ecological Indicators, 53, 171-181. https://doi.org/10.1016/j.ecoli nd.2015.01.019

Aquiloni, L., Giulianini, P. G., Mosco, A., Guarnaccia, C., Ferrero, E., \& Gherardi, F. (2012). Crustacean hyperglycemic hormone (cHH) as a modulator of aggression in crustacean decapods. PLoS ONE, 7(11), e50047. https://doi.org/10.1371/journal.pone.0050047

Aquiloni, L., Ilhéu, M., \& Gherardi, F. (2005). Habitat use and dispersal of the invasive crayfish Procambarus clarkii in ephemeral water bodies of Portugal. Marine and Freshwater Behaviour and Physiology, 38(4), 225-236.

Araujo, J., Maximino, C., de Brito, T. M., da Silva, A. W. B., Oliveira, K. R. M., Batista, E. d. J. O, ... Gouveia, A. (2012). Behavioral and pharmacological aspects of anxiety in the light/dark preference test. In Allan V. Kalueff, \& Adam Michael Stewart (Eds.), Zebrafish protocols for neurobehavioral research (pp. 191-202). Totowa, NJ: Springer.

Bacqué-Cazenave, J., Cattaert, D., Delbecque, J.-P., \& Fossat, P. (2017). Social harassment induces anxiety-like behaviour in crayfish. Scientific Reports, 7, 39935. https://doi.org/10.1038/srep39935

Banha, F., \& Anastácio, P. M. (2014). Desiccation survival capacities of two invasive crayfish species. Knowledge and Management of Aquatic Ecosystems, 413, 1. https://doi.org/10.1051/kmae/2013084

Baracchi, D., Lihoreau, M., \& Giurfa, M. (2017). Do insects have emotions? Some insights from bumble bees. Frontiers in Behavioral Neuroscience, 11, 157. https://doi.org/10.3389/fnbeh.2017.00157

Barba-Escobedo, P. A., \& Gould, G. G. (2012). Visual social preferences of lone zebrafish in a novel environment: Strain and anxiolytic effects. Genes, Brain and Behavior, 11(3), 366-373. https://doi. org/10.1111/j.1601-183X.2012.00770.x

Barbosa, H. P., Lima-Maximino, M. G., \& Maximino, C. (2019). Acute fluoxetine differently affects aggressive display in zebrafish phenotypes. Aggressive Behavior, 45(1), 62-69. https://doi.org/10.1002/ ab. 21797

Bass, S. L. S., \& Gerlai, R. (2008). Zebrafish (Danio rerio) responds differentially to stimulus fish: The effects of sympatric and allopatric predators and harmless fish. Behavioural Brain Research, 186(1), 107-117. https://doi.org/10.1016/j.bbr.2007.07.037

Belzung, C., \& Lemoine, M. (2011). Criteria of validity for animal models of psychiatric disorders: Focus on anxiety disorders and depression. Biology of Mood \& Anxiety Disorders, 1(1), 9. https://doi. org/10.1186/2045-5380-1-9

Bencan, Z., Sledge, D., \& Levin, E. D. (2009). Buspirone, chlordiazepoxide and diazepam effects in a zebrafish model of anxiety. Pharmacology, Biochemistry, and Behavior, 94(1), 75-80. https://doi.org/10.1016/j. pbb.2009.07.009

Benvenuto, C., Gherardi, F., \& Ilheu, M. (2008). Microhabitat use by the white-clawed crayfish in a Tuscan stream. Journal of Natural History, 42(1-2), 21-33. https://doi.org/10.1080/0022293070 1799090

Bhat, A., Greulich, M. M., \& Martins, E. P. (2015). Behavioral plasticity in response to environmental manipulation among zebrafish 
(Danio rerio) populations. PLoS ONE, 10(4), e0125097. https://doi. org/10.1371/journal.pone.0125097

Blanchard, D. C., \& Blanchard, R. J. (1988). Ethoexperimental approaches to the biology of emotion. Annual Review of Psychology, 39(1), 43-68. https://doi.org/10.1146/annurev.ps.39.020188.000355

Blank, M., Guerim, L. D., Cordeiro, R. F., \& Vianna, M. R. M. (2009). A onetrial inhibitory avoidance task to zebrafish: Rapid acquisition of an NMDA-dependent long-term memory. Neurobiology of Learning and Memory, 92(4), 529-534. https://doi.org/10.1016/j.nlm.2009.07.001

Blundon, J. A., \& Bittner, G. D. (1992). Effects of ethanol and other drugs on excitatory and inhibitory neurotransmission in the crayfish. Journal of Neurophysiology, 67(3), 576-587. https://doi.org/10.1152/ jn.1992.67.3.576

Bovbjerg, R. V. (1956). Some factors affecting aggressive behavior in crayfish. Physiological Zoology, 29(2), 127-136. https://doi.org/10.1086/ physzool.29.2.30152201

Bretaud, S., Li, Q., Lockwood, B. L., Kobayashi, K., Lin, E., \& Guo, S. (2007). A choice behavior for morphine reveals experience-dependent drug preference and underlying neural substrates in developing larval zebrafish. Neuroscience, 146(3), 1109-1116. https://doi.org/10.1016/j. neuroscience.2006.12.073

Broekkamp, C. L. E., Berendsen, H. H. G., Jenck, F., \& Van Delft, A. M. L. (1989). Animal models for anxiety and response to serotonergic drugs. Psychopathology, 22(Suppl. 1), 2-12. https://doi.org/10.1159/000284620

Brown, J. S., Laundré, J. W., \& Gurung, M. (1999). The ecology of fear: Optimal foraging, game theory, and trophic interactions. Journal of Mammalogy, 80(2), 385-399. https://doi.org/10.2307/1383287

Bruski, C. A., \& Dunham, D. W. (1987). The importance of vision in agonistic communication of the crayfish Orconectes rusticus. I: An analysis of bout dynamics. Behaviour, 103(1), 83-107.

Buřič, M., Kozák, P., \& Vích, P. (2008). Evaluation of different marking methods for spiny-cheek crayfish (Orconectes limosus). Knowledge and Management of Aquatic Ecosystems, 389, 2.

Cachat, J., Canavello, P., Elegante, M., Bartels, B., Hart, P., Bergner, C., ... Kalueff, A. V. (2010). Modeling withdrawal syndrome in zebrafish. Behavioural Brain Research, 208(2), 371-376. https://doi. org/10.1016/j.bbr.2009.12.004

Cachat, J., Kyzar, E. J., Collins, C., Gaikwad, S., Green, J., Roth, A., ... Kalueff, A. V. (2013). Unique and potent effects of acute ibogaine on zebrafish: The developing utility of novel aquatic models for hallucinogenic drug research. Behavioural Brain Research, 236, 258-269. https://doi.org/10.1016/j.bbr.2012.08.041

Cachat, J., Stewart, A., Grossman, L., Gaikwad, S., Kadri, F., Chung, K. M., ... Kalueff, A. V. (2010). Measuring behavioral and endocrine responses to novelty stress in adult zebrafish. Nature Protocols, 5(11), 1786. https://doi.org/10.1038/nprot.2010.140

Campos, A.C., Fogaca, M. V., Aguiar, D. C., \& Guimaraes, F. S. (2013). Animal models of anxiety disorders and stress. Revista Brasileira de Psiquiatria, 35, S101-S111. https://doi.org/10.1590/1516-4446-2013-1139

Capinha, C., Leung, B., \& Anastácio, P. (2011). Predicting worldwide invasiveness for four major problematic decapods: An evaluation of using different calibration sets. Ecography, 34(3), 448-459. https:// doi.org/10.1111/j.1600-0587.2010.06369.x

Cheung, E., Chatterjee, D., \& Gerlai, R. (2014). Subcutaneous dye injection for marking and identification of individual adult zebrafish (Danio rerio) in behavioral studies. Behavior Research Methods, 46(3), 619-624. https://doi.org/10.3758/s13428-013-0399-x

Chiavegatto, S., Dawson, V. L., Mamounas, L. A., Koliatsos, V. E., Dawson, T. M., \& Nelson, R. J. (2001). Brain serotonin dysfunction accounts for aggression in male mice lacking neuronal nitric oxide synthase. Proceedings of the National Academy of Sciences of the United States of America, 98(3), 1277-1281. https://doi.org/10.1073/pnas.031487198

Cho, H., Lee, C.-J., Choi, J., Hwang, J., \& Lee, Y. (2012). Anxiolytic effects of an acetylcholinesterase inhibitor, physostigmine, in the adult zebrafish. Animal Cells and Systems, 16(3), 198-206. https://doi. org/10.1080/19768354.2011.642084
Chucholl, C., Morawetz, K., \& Groß, H. (2012). The clones are comingstrong increase in Marmorkrebs [Procambarus fallax (Hagen, 1870) f. virginalis] records from Europe. Aquatic Invasions, 7(4), 511-519. https://doi.org/10.3391/ai.2012.7.4.008

Cousin, X., Daouk, T., Péan, S., Lyphout, L., Schwartz, M.-E., \& Bégout, M.-L. (2012). Electronic individual identification of zebrafish using radio frequency identification (RFID) microtags. Journal of Experimental Biology, 215(16), 2729-2734. https://doi.org/10.1242/ jeb.071829

Crandall, K., \& Buhay, J. E. (2008). Global diversity of crayfish (Astacidae, Cambaridae, and Parastacidae-Decapoda) in freshwater. Hydrobiologia, 595, 295-301). Springer.

Curran, K. P., \& Chalasani, S. H. (2012). Serotonin circuits and anxiety: What can invertebrates teach us? Invertebrate Neuroscience, 12(2), 81-92. https://doi.org/10.1007/s10158-012-0140-y

Dahlbom, S. J., Backström, T., Lundstedt-Enkel, K., \& Winberg, S. (2012). Aggression and monoamines: Effects of sex and social rank in zebrafish (Danio rerio). Behavioural Brain Research, 228(2), 333-338. https:// doi.org/10.1016/j.bbr.2011.12.011

Davis, M., Walker, D. L., \& Lee, Y. (1997). Amygdala and bed nucleus of the stria terminalis: Differential roles in fear and anxiety measured with the acoustic startle reflex. Philosophical Transactions of the Royal Society of London. Series B, Biological Sciences, 352(1362), 1675-1687. https://doi.org/10.1098/rstb.1997.0149

de Abreu, M. S., Friend, A. J., Amstislavskaya, T. G., \& Kalueff, A. V. (2018). Commentary: Establishing zebrafish as a model to study the anxiolytic effects of scopolamine. Frontiers in Pharmacology, 9, 1-4. https://doi.org/10.3389/fphar.2018.00293

de Abreu, M. S., Giacomini, A. C. V. V., Echevarria, D. J., \& Kalueff, A. V. (2019). Legal aspects of zebrafish neuropharmacology and neurotoxicology research. Regulatory Toxicology and Pharmacology, 101, 65-70. https://doi.org/10.1016/j.yrtph.2018.11.007

de Abreu, M. S., Giacomini, A. C. V. V., Genario, R., dos Santos, B. E., da Rosa, L. G., Demin, K. A., ... Kalueff, A. V. (2019). Neuropharmacology, pharmacogenetics and pharmacogenomics of aggression: The zebrafish model. Pharmacological Research, 141, 602-608. https://doi. org/10.1016/j.phrs.2019.01.044

de Mooij-van Malsen, A. J. G., Vinkers, C. H., Peterse, D. P., Olivier, B., \& Kas, M. J. H. (2011). Cross-species behavioural genetics: A starting point for unravelling the neurobiology of human psychiatric disorders. Progress in Neuro-Psychopharmacology and Biological Psychiatry, 35(6), 1383-1390. https://doi.org/10.1016/j. pnpbp.2010.10.003

Dekeyne, A., Denorme, B., Monneyron, S., \& Millan, M. J. (2000). Citalopram reduces social interaction in rats by activation of serotonin (5-HT)2C receptors. Neuropharmacology, 39(6), 1114-1117. https://doi.org/10.1016/S0028-3908(99)00268-3

Delcourt, J., Ovidio, M., Denoël, M., Muller, M., Pendeville, H., Deneubourg, J.-L., \& Poncin, P. (2018). Individual identification and marking techniques for zebrafish. Reviews in Fish Biology and Fisheries, 28(4), 839-864. https://doi.org/10.1007/s11160-018-9537-y

Delcourt, J., \& Poncin, P. (2012). Shoals and schools: Back to the heuristic definitions and quantitative references. Reviews in Fish Biology and Fisheries, 22(3), 595-619. https://doi.org/10.1007/s1116 0-012-9260-z

Delibes, M., \& Adrián, I. (1987). Effects of crayfish introduction on otter Lutra lutra food in the Donana National Park, SW Spain. Biological Conservation, 42(2), 153-159.

Demin, K. A., Sysoev, M., Chernysh, M. V., Savva, A. K., Koshiba, M., Wappler-Guzzetta, E. A., ... Kalueff, A. V. (2019). Animal models of major depressive disorder and the implications for drug discovery and development. Expert Opinion on Drug Discovery, 14(4), 365-378. https://doi.org/10.1080/17460441.2019.1575360

Denenberg, V. H. (1969). Open-field behavior in the rat: What does it mean? Annals of the New York Academy of Sciences, 159(3), 852-859. https://doi.org/10.1111/j.1749-6632.1969.tb12983.x 
Detrich lii, H. W., Westerfield, M., \& Zon, L. I. (1998). Overview of the zebrafish system. In H. William Detrich III, Monte Westerfield, \& Leonard I. Zon (Eds), Methods in cell biology (Vol. 59, pp. 3-10). Elsevier.

Dingman, S., Hurlburt, L., \& Otte, M. (2009). Exploring new compounds for functional imaging using a crayfish (Procambarus clarkia) aggression paradigm. Perceptual and Motor Skills, 109(2), 487-499.

Drozdz, J. K., Viscek, J., Brudzynski, S. M., \& Mercier, A. J. (2006). Behavioral responses of crayfish to a reflective environment. Journal of Crustacean Biology, 26(4), 463-473. https://doi. org/10.1651/S-2687.1

Dziopa, L., Imeh-Nathaniel, A., Baier, D., Kiel, M., Sameera, S., Brager, A., ... Nathaniel, T. I. (2011). Morphine-conditioned cue alters cFos protein expression in the brain of crayfish. Brain Research Bulletin, 85(6), 385-395. https://doi.org/10.1016/j.brainresbu II.2011.04.003

Eaton, R. C., \& Farley, R. D. (1974). Growth and the reduction of depensation of zebrafish, Brachydanio rerio, reared in the laboratory. Copeia, 204-209.

Egan, R. J., Bergner, C. L., Hart, P. C., Cachat, J. M., Canavello, P. R., Elegante, M. F., ... Kalueff, A. V. (2009). Understanding behavioral and physiological phenotypes of stress and anxiety in zebrafish. Behavioural Brain Research, 205(1), 38-44. https://doi.org/10.1016/j. bbr.2009.06.022

Engeszer, R. E., Da Barbiano, L. A., Ryan, M. J., \& Parichy, D. M. (2007). Timing and plasticity of shoaling behaviour in the zebrafish, Danio rerio. Animal Behaviour, 74(5), 1269-1275. https://doi.org/10.1016/j. anbehav.2007.01.032

Engeszer, R. E., Patterson, L. B., Rao, A. A., \& Parichy, D. M. (2007) Zebrafish in the wild: A review of natural history and new notes from the field. Zebrafish, 4(1), 21-40. https://doi.org/10.1089/ zeb.2006.9997

Engeszer, R. E., Ryan, M. J., \& Parichy, D. M. (2004). Learned social preference in zebrafish. Current Biology, 14(10), 881-884. https://doi. org/10.1016/j.cub.2004.04.042

Farhan, M., \& Haleem, D. J. (2016). Anxiolytic profile of fluoxetine as monitored following repeated administration in animal rat model of chronic mild stress. Saudi Pharmaceutical Journal, 24(5), 571-578. https://doi.org/10.1016/j.jsps.2015.03.006

Ferrari, M. C. O., Sih, A., \& Chivers, D. P. (2009). The paradox of risk allocation: A review and prospectus. Animal Behaviour, 78(3), 579-585. https://doi.org/10.1016/j.anbehav.2009.05.034

Ferrari, P. F., Palanza, P., Parmigiani, S., de Almeida, R. M., \& Miczek, K. A. (2005). Serotonin and aggressive behavior in rodents and nonhuman primates: Predispositions and plasticity. European Journal of Pharmacology, 526(1-3), 259-273. https://doi.org/10.1016/j. ejphar.2005.10.002

Figler, M. H., Finkelstein, J. E., Twum, M., \& Peeke, H. V. S. (1995). Intruding male red swamp crayfish, Procambarus clarkii, immediately dominate members of established communities of smaller, mixed-sex conspecifics. Aggressive Behavior, 21(3), 225-236.

Fior, D., Dametto, F., Fagundes, M., Santos da Rosa, J. G., Sander de Abreu, M., Koakoski, G., ... Barcellos, L. J. G. (2018). Divergent action of fluoxetine in zebrafish according to responsivity to novelty. Scientific Reports, 8, 1-9. https://doi.org/10.1038/s41598-018-32263-y

Fontana, B. D., Meinerz, D. L., Rosa, L. V. C., Mezzomo, N. J., Silveira, A., Giuliani, G. S., ... Rosemberg, D. B. (2016). Modulatory action of taurine on ethanol-induced aggressive behavior in zebrafish. Pharmacology, Biochemistry and Behavior, 141, 18-27. https://doi. org/10.1016/j.pbb.2015.11.011

Fossat, P., Bacqué-Cazenave, J., De Deurwaerdère, P., Cattaert, D., \& Delbecque, J.-P. (2015). Serotonin, but not dopamine, controls stress response and anxiety-like behavior in crayfish, Procambarus clarkii. Journal of Experimental Biology, 218(17), 2745-2752.

Fossat, P., Bacqué-Cazenave, J., De Deurwaerdère, P., Delbecque, J.-P., \& Cattaert, D. (2014). Anxiety-like behavior in crayfish is controlled by serotonin. Science, 344(6189), 1293. https://doi.org/10.1126/scien ce.1248811
Gallup, G. G. Jr. (1974). Animal hypnosis: Factual status of a fictional concept. Psychological Bulletin, 81(11), 836. https://doi.org/10.1037/ h0037227

Gallup, G. G. (1979). Tonic immobility as a measure of fear in domestic fowl. Animal Behaviour, 27(1), 316-317. https://doi.org/10.1016/ 0003-3472(79)90159-3

Gemmel, M., Hazlett, M., Bögi, E., De Lacalle, S., Hill, L. A., Kokras, N., ... Pawluski, J. L. (2017). Perinatal fluoxetine effects on social play, the HPA system, and hippocampal plasticity in pre-adolescent male and female rats: Interactions with pre-gestational maternal stress. Psychoneuroendocrinology, 84, 159-171. https://doi.org/10.1016/j. psyneuen.2017.07.480

Gerhard, G. S., Kauffman, E. J., Wang, X., Stewart, R., Moore, J. L., Kasales, C. J., \& Cheng, K. C. (2002). Life spans and senescent phenotypes in two strains of Zebrafish (Danio rerio). Experimental Gerontology, 37(8-9), 1055-1068.

Gerlai, R. (2014). Fish in behavior research: Unique tools with a great promise!. Journal of Neuroscience Methods, 234, 54-58. https://doi. org/10.1016/j.jneumeth.2014.04.015

Gerlai, R., Lahav, M., Guo, S., \& Rosenthal, A. (2000). Drinks like a fish: Zebra fish (Danio rerio) as a behavior genetic model to study alcohol effects. Pharmacology Biochemistry and Behavior, 67(4), 773-782. https://doi.org/10.1016/S0091-3057(00)00422-6

Gherardi, F. (2013). Crayfish as global invaders: Distribution, impact on ecosystem services and management options. Freshwater Crayfish, 19(2), 177-187.

Gherardi, F., \& Barbaresi, S. (2000). Invasive crayfish: Activity patterns of Procambarus clarkii in the rice fields of the Lower Guadalquivir (Spain). Archiv für Hydrobiologie, 150, 153-168. https://doi.org/10.1127/archi v-hydrobiol/150/2000/153

Gherardi, F., Barbaresi, S., \& Salvi, G. (2000). Spatial and temporal patterns in the movement of Procambarus clarkii, an invasive crayfish. Aquatic Sciences, 62(2), 179-193. https://doi.org/10.1007/PL000 01330

Giacomini, A. C. V. V., Abreu, M. S., Giacomini, L. V., Siebel, A. M., Zimerman, F. F., Rambo, C. L., ... Barcellos, L. J. G. (2016). Fluoxetine and diazepam acutely modulate stress induced-behavior. Behavioral Brain Research, 296, 301-310. https://doi.org/10.1016/j.bbr. 2015.09.027

Gorissen, M., Manuel, R., Pelgrim, T. N. M., Mes, W., de Wolf, M. J. S., Zethof, J., ... van den Bos, R. (2015). Differences in inhibitory avoidance, cortisol and brain gene expression in $T L$ and $A B$ zebrafish. Genes, Brain and Behavior, 14(5), 428-438. https://doi.org/10.1111/ gbb.12220

Green, J., Collins, C., Kyzar, E. J., Pham, M., Roth, A., Gaikwad, S., ... Kalueff, A. V. (2012). Automated high-throughput neurophenotyping of zebrafish social behavior. Journal of Neuroscience Methods, 210(2), 266-271. https://doi.org/10.1016/j.jneumeth.2012.07.017

Griebel, G. (1995). 5-Hydroxytryptamine-interacting drugs in animal models of anxiety disorders: More than 30 years of research. Pharmacology \& Therapeutics, 65(3), 319-395. https://doi. org/10.1016/0163-7258(95)98597-J

Grossman, L., Utterback, E., Stewart, A., Gaikwad, S., Chung, K. M., Suciu, C., ... Kalueff, A. V. (2010). Characterization of behavioral and endocrine effects of LSD on zebrafish. Behavioural Brain Research, 214(2), 277-284. https://doi.org/10.1016/j.bbr.2010.05.039

Gutekunst, J., Andriantsoa, R., Falckenhayn, C., Hanna, K., Stein, W., Rasamy, J., \& Lyko, F. (2018). Clonal genome evolution and rapid invasive spread of the marbled crayfish. Nature Ecology \& Evolution, 2(3), 567-573. https://doi.org/10.1038/s41559-018-0467-9

Hamilton, T. J., Kwan, G. T., Gallup, J., \& Tresguerres, M. (2016). Acute fluoxetine exposure alters crab anxiety-like behaviour, but not aggressiveness. Scientific Reports, 6, 19850. https://doi.org/10.1038/ srep19850

Hamilton, T. J., Morrill, A., Lucas, K., Gallup, J., Harris, M., Healey, M., ... Tresguerres, M. (2017). Establishing zebrafish as a model to study 
the anxiolytic effects of scopolamine. Scientific Reports, 7, 15081. https://doi.org/10.1038/s41598-017-15374-w

Hånell, A., \& Marklund, N. (2014). Structured evaluation of rodent behavioral tests used in drug discovery research. Frontiers in Behavioral Neuroscience, 8, 252. https://doi.org/10.3389/fnbeh.2014.00252

Harro, J. (2018). Animals, anxiety, and anxiety disorders: How to measure anxiety in rodents and why. Behavioural Brain Research, 352, 81-93. https://doi.org/10.1016/j.bbr.2017.10.016

Hayes II, W. A. (1975). Behavioral Components of Social Interactions in the Crayfish Procambarus gracilis (Bundy) (Decapoda: Cambaridae). Proceedings of the Oklahoma Academy of Science., 55, 1-5.

Herculano, A. M., \& Maximino, C. (2014). Serotonergic modulation of zebrafish behavior: Towards a paradox. Progress in NeuroPsychopharmacology and Biological Psychiatry, 55, 50-66. https://doi. org/10.1016/j.pnpbp.2014.03.008

Hobbs, H. H. (1972). Biota of freshwater ecosystems identification manual no. 9, crayfishes (astacidae) of North and Middle America. Copy available from GPO sup doc as EP 1. 16: 18050 ELD 05/72\$ 3. 25.

Holdich, D. M. (1988). The dangers of introducing alien animals with particular references to crayfish. Freshwater Crayfish, 77, XV-XXX.

Holdich, D. M. (2001). Biology of freshwater crayfish-Oxford England. Oxford: Wiley-Blackwell Publishing.

Howe, K., Clark, M. D., Torroja, C. F., Torrance, J., Berthelot, C., Muffato, M., ... Stemple, D. L. (2013). The zebrafish reference genome sequence and its relationship to the human genome. Nature, 496(7446), 498-503. https://doi.org/10.1038/nature12111

Huber, R., \& Delago, A. (1998). Serotonin alters decisions to withdraw in fighting crayfish, Astacus astacus: The motivational concept revisited. Journal of Comparative Physiology A, 182(5), 573-583. https:// doi.org/10.1007/s003590050204

Huber, R., Panksepp, J. B., Nathaniel, T., Alcaro, A., \& Panksepp, J. (2011). Drug-sensitive reward in crayfish: An invertebrate model system for the study of SEEKING, reward, addiction, and withdrawal. Neuroscience and Biobehavioral Reviews, 35(9), 1847-1853. https:// doi.org/10.1016/j.neubiorev.2010.12.008

Huner, J. V., Barr, J. E., \& Coleman, E. B. (1991). Red swamp crawfish: Biology and exploitation. Baton Rouge, Louisiana: Louisiana Sea Grant College Program.

Idalencio, R., Kalichak, F., Rosa, J. G. S., Oliveira, T. A. D., Koakoski, G., Gusso, D., ... Barcellos, L. J. G. (2015). Waterborne risperidone decreases stress response in zebrafish. PLoS ONE, 10(10), e0140800. https://doi.org/10.1371/journal.pone.0140800

Imeh-Nathaniel, A., Orfanakos, V., Wormack, L., Huber, R., \& Nathaniel, T. I. (2019). The crayfish model (Orconectes rusticus), epigenetics and drug addiction research. Pharmacology Biochemistry and Behavior, 183, 38-45. https://doi.org/10.1016/j.pbb.2019.06.003

Imeh-Nathaniel, A., Rincon, N., Orfanakos, V. B., Brechtel, L., Wormack, L., Richardson, E., ... Nathaniel, T. I. (2017). Effects of chronic cocaine, morphine and methamphetamine on the mobility, immobility and stereotyped behaviors in crayfish. Behavioural Brain Research, 332, 120-125. https://doi.org/10.1016/j.bbr.2017.05.069

Irons, T. D., MacPhail, R. C., Hunter, D. L., \& Padilla, S. (2010). Acute neuroactive drug exposures alter locomotor activity in larval zebrafish. Neurotoxicology and Teratology, 32(1), 84-90. https://doi. org/10.1016/j.ntt.2009.04.066

Isely, J. J., \& Eversole, A. G. (1998). Tag retention, growth, and survival of red swamp crayfish Procambarus clarkii marked with coded wire tags. Transactions of the American Fisheries Society, 127(4), 658-660.

Issa, F. A., Adamson, D. J., \& Edwards, D. H. (1999). Dominance hierarchy formation in juvenile crayfish Procambarus clarkii. Journal of Experimental Biology, 202(24), 3497-3506.

Jensen, F. B., Nikinmaa, M., \& Weber, R. E. (1993). Environmental perturbations of oxygen transport in teleost fishes: Causes, consequences and compensations. In J. Cliff Rankin, Frank B. Jensen (Eds.), Fish ecophysiology (pp. 161-179). Springer.
Jiménez-Morales, N., Mendoza-Ángeles, K., Porras-Villalobos, M., Ibarra-Coronado, E., Roldán-Roldán, G., \& Hernández-Falcón, J. (2018). Who is the boss? Individual recognition memory and social hierarchy formation in crayfish. Neurobiology of Learning and Memory, 147, 79-89. https://doi.org/10.1016/j.nlm.2017.11.017

Johnson, A., \& Hamilton, T. J. (2017). Modafinil decreases anxiety-like behaviour in zebrafish. PeerJ, 5, e2994. https://doi.org/10.7717/ peerj. 2994

Kalueff, A. V., Kaluyeva, A., \& Maillet, E. L. (2017). Anxiolytic-like effects of noribogaine in zebrafish. Behavioural Brain Research, 330, 63-67. https://doi.org/10.1016/j.bbr.2017.05.008

Kalueff, A. V., Stewart, A. M., \& Gerlai, R. (2014). Zebrafish as an emerging model for studying complex brain disorders. Trends in Pharmacological Sciences, 35(2), 63-75. https://doi.org/10.1016/j.tips.2013.12.002

Kalueff, A. V., Gebhardt, M., Stewart, A. M., Cachat, J. M., Brimmer, M., Chawla, J. S., ... Zebrafish Neuroscience Research Consortium. (2013). Towards a comprehensive catalog of zebrafish behavior 1.0 and beyond. Zebrafish, 10(1), 70-86. https://doi.org/10.1089/ zeb.2012.0861

Kas, M. J. H., Krishnan, V., Gould, T. D., Collier, D. A., Olivier, B., Lesch, K.-P., ... Castrén, E. (2011). Advances in multidisciplinary and crossspecies approaches to examine the neurobiology of psychiatric disorders. European Neuropsychopharmacology, 21(7), 532-544. https:// doi.org/10.1016/j.euroneuro.2010.12.001

Kimmel, C. B., Ballard, W. W., Kimmel, S. R., Ullmann, B., \& Schilling, T. F. (1995). Stages of embryonic development of the zebrafish. Developmental Dynamics, 203(3), 253-310.

Kramer, D. L. (1987). Dissolved oxygen and fish behavior. Environmental Biology of Fishes, 18(2), 81-92. https://doi.org/10.1007/BF00002597

Kramer, D. L., \& Mehegan, J. P. (1981). Aquatic surface respiration, an adaptive response to hypoxia in the guppy, Poecilia reticulata (Pisces, Poeciliidae). Environmental Biology of Fishes, 6(3), 299-313. https:// doi.org/10.1007/BF00005759

Kysil, E. V., Meshalkina, D. A., Frick, E. E., Echevarria, D. J., Rosemberg, D. B., Maximino, C., ... Kalueff, A. V. (2017). Comparative analyses of zebrafish anxiety-like behavior using conflict-based novelty tests. Zebrafish, 14(3), 197-208. https://doi.org/10.1089/zeb.2016.1415

Kyzar, E. J., Collins, C., Gaikwad, S., Green, J., Roth, A., Monnig, L., ... Kalueff, A. V. (2012). Effects of hallucinogenic agents mescaline and phencyclidine on zebrafish behavior and physiology. Progress in Neuro-Psychopharmacology \& Biological Psychiatry, 37(1), 194-202. https://doi.org/10.1016/j.pnpbp.2012.01.003

Lakstygal, A. M., de Abreu, M. S., \& Kalueff, A. V. (2018). Zebrafish models of epigenetic regulation of CNS functions. Brain Research Bulletin, 142, 344-351. https://doi.org/10.1016/j.brainresbull.2018.08.022

Laundré, J. W., Hernández, L., \& Ripple, W. J. (2010). The landscape of fear: Ecological implications of being afraid. Open Ecology Journal, 3 , $1-7$.

Lodge, D. M., Deines, A., Gherardi, F., Yeo, D. C. J., Arcella, T., Baldridge, A. K., ... Zeng, Y. (2012). Global introductions of crayfishes: Evaluating the impact of species invasions on ecosystem services. Annual Review of Ecology, Evolution, and Systematics, 43, 449-472. https:// doi.org/10.1146/annurev-ecolsys-111511-103919

López-Patiño, M. A., Yu, L., Cabral, H., \& Zhdanova, I. V. (2008). Anxiogenic effects of cocaine withdrawal in zebrafish. Physiology \& Behavior, 93(1), 160-171. https://doi.org/10.1016/j.physbeh.2007.08.013

Loureiro, T. G., Anastácio, P. M. S. G., Araujo, P. B., Souty-Grosset, C., \& Almerão, M. P. (2015). Red swamp crayfish: Biology, ecology and invasion-An overview. Nauplius, 23, 1-19. https://doi.org/10.1590/ S0104-64972014002214

Maier, S. F. (1993). Learned helplessness: Relationships with fear and anxiety. In S. C. Stanford \& P. Salmon (Eds.), Stress: From synapse to syndrome (pp. 207-243). San Diego, CA, US: Academic Press.

Manuel, R., Gorissen, M., Zethof, J., Ebbesson, L. O. E., van de Vis, H., Flik, G., \& van den Bos, R. (2014). Unpredictable chronic stress decreases inhibitory avoidance learning in Tuebingen long-fin 
zebrafish: Stronger effects in the resting phase than in the active phase. The Journal of Experimental Biology, 217(21), 3919. https://doi. org/10.1242/jeb.109736

Marcon, M., Herrmann, A. P., Mocelin, R., Rambo, C. L., Koakoski, G., Abreu, M. S., ... Piato, A. L. (2016). Prevention of unpredictable chronic stress-related phenomena in zebrafish exposed to bromazepam, fluoxetine and nortriptyline. Psychopharmacology, 233(21-22), 3815-3824. https://doi.org/10.1007/s00213-016-4408-5

Martin, P., Dorn, N. J., Kawai, T., van der Heiden, C., \& Scholtz, G. (2010). The enigmatic Marmorkrebs (marbled crayfish) is the parthenogenetic form of Procambarus fallax (Hagen, 1870). Contributions to Zoology, 79(3), 107-118. https://doi.org/10.1163/18759 866-07903003

Mathur, P., \& Guo, S. (2010). Use of zebrafish as a model to understand mechanisms of addiction and complex neurobehavioral phenotypes. Neurobiology of Disease, 40(1), 66-72. https://doi.org/10.1016/j. nbd.2010.05.016

Maximino, C., da Silva, A. W. B., Araújo, J., Lima, M. G., Miranda, V., Puty, B., ... Herculano, A. M. (2014). Fingerprinting of psychoactive drugs in zebrafish anxiety-like behaviors. PLoS ONE, 9(7), e103943. https:// doi.org/10.1371/journal.pone.0103943

Maximino, C., de Brito, T. M., da Silva Batista, A. W., Herculano, A. M., Morato, S., \& Gouveia, A. Jr. (2010). Measuring anxiety in zebrafish: A critical review. Behavioural Brain Research, 214(2), 157-171. https:// doi.org/10.1016/j.bbr.2010.05.031

Maximino, C., De Brito, T. M., de Mattos Dias, C. A. G., Gouveia, A. Jr., \& Morato, S. (2010). Scototaxis as anxiety-like behavior in fish. Nature Protocols, 5(2), 209. https://doi.org/10.1038/nprot.2009.225

Maximino, C., \& Herculano, A. M. (2010). A review of monoaminergic neuropsychopharmacology in zebrafish. Zebrafish, 7(4), 359-378. https://doi.org/10.1089/zeb.2010.0669

Maximino, C., Lima, M. G., Costa, C. C., Guedes, I. M. L., \& Herculano, A. M. (2014). Fluoxetine and WAY 100,635 dissociate increases in scototaxis and analgesia induced by conspecific alarm substance in zebrafish (Danio rerio Hamilton 1822). Pharmacology Biochemistry and Behavior, 124, 425-433. https://doi.org/10.1016/j.pbb.2014.07.003

Maximino, C., de Brito, T.M., Dias, C. A. G. D. M., Gouveia, A., \& Morato, S. (2010). Scototaxis as anxiety-like behavior in fish. Nature Protocols, 5, 209. https://doi.org/10.1038/nprot.2009.225

Maximino, C., Silva, R. X. D. C., da Silva, S. D. N. S., Rodrigues, L. D. S. D. S., Barbosa, H., de Carvalho, T. S., ... Herculano, A. M. (2015). Nonmammalian models in behavioral neuroscience: Consequences for biological psychiatry. Frontiers in Behavioral Neuroscience, 9, 233. https ://doi.org/10.3389/fnbeh.2015.00233

Maximino, C., \& van der Staay, F. J. (2019). Behavioral models in psychopathology: Epistemic and semantic considerations. Behavioral and Brain Functions, 15(1), 1. https://doi.org/10.1186/s12993-019-0152-4

Meriweather, F. (1986). Tagging and marking crawfish (Procambarus clarkii) in a population estimation study. Journal of the Arkansas Academy of Science, 40(1), 45-47.

Meshalkina, D. A., Kysil, E. V., Antonova, K. A., Demin, K. A., Kolesnikova, T. O., Khatsko, S. L., ... Kalueff, A. V. (2018). The effects of chronic amitriptyline on zebrafish behavior and monoamine neurochemistry. Neurochemical Research, 43(6), 1191-1199. https://doi.org/10.1007/ s11064-018-2536-5

Miller, N., \& Gerlai, R. (2007). Quantification of shoaling behaviour in zebrafish (Danio rerio). Behavioural Brain Research, 184(2), 157-166. https://doi.org/10.1016/j.bbr.2007.07.007

Miller, N. Y., \& Gerlai, R. (2011). Shoaling in zebrafish: What we don't know. Reviews in the Neurosciences, 22(1), 17-25. https://doi. org/10.1515/rns.2011.004

Miller, N., Greene, K., Dydinski, A., \& Gerlai, R. (2013). Effects of nicotine and alcohol on zebrafish (Danio rerio) shoaling. Behavioural Brain Research, 240, 192-196. https://doi.org/10.1016/j.bbr.2012. 11.033
Mocelin, R., Herrmann, A. P., Marcon, M., Rambo, C. L., Rohden, A., Bevilaqua, F., ... Piato, A. L. (2015). N-acetylcysteine prevents stressinduced anxiety behavior in zebrafish. Pharmacology Biochemistry and Behavior, 139, 121-126. https://doi.org/10.1016/j.pbb.2015.08.006

Mocelin, R., Marcon, M., D'ambros, S., Mattos, J., Sachett, A., Siebel, A. M., ... Piato, A. (2019). N-acetylcysteine reverses anxiety and oxidative damage induced by unpredictable chronic stress in zebrafish. Molecular Neurobiology, 56(2), 1188-1195. https://doi.org/10.1007/ s12035-018-1165-y

Mohammad, F., Aryal, S., Ho, J., Stewart, J. C., Norman, N. A., Tan, T. L., ... Claridge-Chang, A. (2016). Ancient anxiety pathways influence Drosophila defense behaviors. Current Biology, 26(7), 981-986. https://doi.org/10.1016/j.cub.2016.02.031

Momohara, Y., Kanai, A., \& Nagayama, T. (2013). Aminergic control of social status in crayfish agonistic encounters. PLOS ONE, 8(9), e74489. https://doi.org/10.1371/journal.pone.0074489

Montgomery, K. C. (1955). The relation between fear induced by novel stimulation and exploratory drive. Journal of Comparative and Physiological Psychology, 48(4), 254. https://doi.org/10.1037/h0043788

Moore, P. A. (2007). Agonistic Behavior in Freshwater Crayfish The Influence of Intrinsic and Extrinsic Factors on Aggressive Encounters and Dominance. In E. J. Duffy, \& M. Thiel (Eds.), Evolutionary ecology of social and sexual systems: Crustaceans as model organisms (pp. 90-114). New York, NY: Oxford University Press.

Muto, A., Taylor, M. R., Suzawa, M., Korenbrot, J. I., \& Baier, H. (2013). Glucocorticoid receptor activity regulates light adaptation in the zebrafish retina. Frontiers in Neural Circuits, 7, 145. https://doi. org/10.3389/fncir.2013.00145

Norton, W. H., \& Bally-Cuif, L. (2012). Unravelling the proximate causes of the aggression-boldness behavioural syndrome in zebrafish. Behaviour, 149(10-12), 1063-1079. https://doi.org/10.1163/15685 39X-00003012

Norton, W. H. J., Stumpenhorst, K., Faus-Kessler, T., Folchert, A., Rohner, N., Harris, M. P., ... Bally-Cuif, L. (2011). Modulation of Fgfr1a signaling in zebrafish reveals a genetic basis for the aggression-boldness syndrome. Journal of Neuroscience, 31(39), 13796-13807. https://doi. org/10.1523/JNEUROSCI.2892-11.2011

Nowicki, M., Tran, S., Muraleetharan, A., Markovic, S., \& Gerlai, R. (2014). Serotonin antagonists induce anxiolytic and anxiogenic-like behavior in zebrafish in a receptor-subtype dependent manner. Pharmacology Biochemistry and Behavior, 126, 170-180. https://doi.org/10.1016/j. pbb.2014.09.022

Nuss, P. (2015). Anxiety disorders and GABA neurotransmission: A disturbance of modulation. Neuropsychiatric Disease and Treatment, 11, 165-175.

Oatley, K., \& Johnson-Laird, P. N. (2014). Cognitive approaches to emotions. Trends in Cognitive Sciences, 18(3), 134-140. https://doi. org/10.1016/j.tics.2013.12.004

Ogawa, S., Ng, K. W., Ramadasan, P. N., Nathan, F. M., \& Parhar, I. S. (2012). Habenular Kiss1 neurons modulate the serotonergic system in the brain of zebrafish. Endocrinology, 153(5), 2398-2407. https:// doi.org/10.1210/en.2012-1062

Oliveira, R. F., Silva, J. F., \& Simões, J. M. (2011). Fighting zebrafish: Characterization of aggressive behavior and winner-loser effects. Zebrafish, 8(2), 73-81. https://doi.org/10.1089/zeb.2011.0690

Olivier, B., \& Mos, J. (1992). Rodent models of aggressive behavior and serotonergic drugs. Progress in Neuro-Psychopharmacology and Biological Psychiatry, 16(6), 847-870. https://doi. org/10.1016/0278-5846(92)90104-M

Pancotto, L., Mocelin, R., Marcon, M., Herrmann, A. P., \& Piato, A. (2018). Anxiolytic and anti-stress effects of acute administration of acetyl-L-carnitine in zebrafish. PeerJ, 6, e5309. https://doi.org/10.7717/peerj.5309

Parichy, D. M. (2015). Advancing biology through a deeper understanding of zebrafish ecology and evolution. eLife, 4, 1-11. https://doi. org/10.7554/eLife.05635 
Patiño, M. A. L., Yu, L., Yamamoto, B. K., \& Zhdanova, I. V. (2008) Gender differences in zebrafish responses to cocaine withdrawal. Physiology \& Behavior, 95(1-2), 36-47. https://doi.org/10.1016/j. physbeh.2008.03.021

Petrunich-Rutherford, M. L. (2019). Chronic fluoxetine treatment of juvenile zebrafish. PeerJ, 7, e6407. https://doi.org/10.7717/peerj.6407

Pitcher, T. J. (1983). Heuristic definitions of fish shoaling behaviour. Animal Behaviour, 31(2), 611-613. https://doi.org/10.1016/S0003 $-3472(83) 80087-6$

Ponzoni, L., Daniela, B., \& Sala, M. (2016). Abuse potential of methylenedioxymethamphetamine (MDMA) and its derivatives in zebrafish: Role of serotonin 5HT2-type receptors. Psychopharmacology, 233(15), 3031-3039. https://doi.org/10.1007/s00213-016-4352-4

Ponzoni, L., Sala, M., \& Braida, D. (2016). Ritanserin-sensitive receptors modulate the prosocial and the anxiolytic effect of MDMA derivatives, DOB and PMA, in zebrafish. Behavioural Brain Research, 314, 181-189. https://doi.org/10.1016/j.bbr.2016.08.009

Ramalho, R. O., \& Anastácio, P. M. (2015). Factors inducing overland movement of invasive crayfish (Procambarus clarkii) in a ricefield habitat. Hydrobiologia, 746(1), 135-146. https://doi.org/10.1007/s1075 0-014-2052-9

Ramalho, R. O., McClain, W. R., \& Anastácio, P. (2010). An effective and simple method of temporarily marking crayfish. Freshwater Crayfish, 17(1), 57-60.

Rambo, C. L., Mocelin, R., Marcon, M., Villanova, D., Koakoski, G., de Abreu, M. S., ... Bonan, C. D. (2017). Gender differences in aggression and cortisol levels in zebrafish subjected to unpredictable chronic stress. Physiology \& Behavior, 171, 50-54. https://doi.org/10.1016/j. physbeh.2016.12.032

Rees, B. B., Sudradjat, F. A., \& Love, J. W. (2001). Acclimation to hypoxia increases survival time of zebrafish, Danio rerio, during lethal hypoxia. Journal of Experimental Zoology, 289(4), 266-272. https:// doi.org/10.1002/1097-010X(20010401/30)289:4<266:AIDJEZ7>3.0.CO;2-5

Reynolds, J. D. (2011). A review of ecological interactions between crayfish and fish, indigenous and introduced. Knowledge and Management of Aquatic Ecosystems, 401, 21.

Rhoades, R. (1962). Further studies on Ohio crayfishes: Cases of sympatry of stream species in southern Ohio. Ohio Journal of Science, 62, 27-33.

Riehl, R., Kyzar, E., Allain, A., Green, J., Hook, M., Monnig, L., ... Kalueff, A. V. (2011). Behavioral and physiological effects of acute ketamine exposure in adult zebrafish. Neurotoxicology and Teratology, 33(6), 658-667. https://doi.org/10.1016/j.ntt.2011.05.011

Ruuskanen, J. O., Peitsaro, N., Kaslin, J. V. M., Panula, P., \& Scheinin, M. (2005). Expression and function of $\alpha 2$-adrenoceptors in zebrafish: Drug effects, mRNA and receptor distributions. Journal of Neurochemistry, 94(6), 1559-1569. https://doi. org/10.1111/j.1471-4159.2005.03305.x

Sánchez, C., \& Meier, E. (1997). Behavioral profiles of SSRIs in animal models of depression, anxiety and aggression. Are they all alike? Psychopharmacology, 129(3), 197-205. https://doi.org/10.1007/ s002130050181

Sato, D., \& Nagayama, T. (2012). Development of agonistic encounters in dominance hierarchy formation in juvenile crayfish. The Journal of Experimental Biology, 215(7), 1210. https://doi.org/10.1242/jeb.066191

Savio, L. E. B., Vuaden, F. C., Piato, A. L., Bonan, C. D., \& Wyse, A. T. S. (2012). Behavioral changes induced by long-term proline exposure are reversed by antipsychotics in zebrafish. Progress in NeuroPsychopharmacology and Biological Psychiatry, 36(2), 258-263. https ://doi.org/10.1016/j.pnpbp.2011.10.002

Schneider, H. (2017). Zebrafish neurobehavioral assays for drug addiction research. In A. V. Kalueff (Ed.), The rights and wrongs of zebrafish: Behavioral phenotyping of zebrafish (pp. 171-205). Cham, Switzerland: Springer International Publishing.
Scholtz, G., Braband, A., Tolley, L., Reimann, A., Mittmann, B., Lukhaup C., ... Vogt, G. (2003). Parthenogenesis in an outsider crayfish. Nature, 421(6925), 806-806. https://doi.org/10.1038/421806a

Schroeder, P. G., \& Sneddon, L. U. (2017). Exploring the efficacy of immersion analgesics in zebrafish using an integrative approach. Applied Animal Behaviour Science, 187, 93-102. https://doi.org/10.1016/j. applanim.2016.12.003

Seibt, K. J., Piato, A. L., da Luz Oliveira, R., Capiotti, K. M., Vianna, M. R., \& Bonan, C. D. (2011). Antipsychotic drugs reverse MK-801-induced cognitive and social interaction deficits in zebrafish (Danio rerio). Behavioural Brain Research, 224(1), 135-139. https://doi. org/10.1016/j.bbr.2011.05.034

Serra, E. L., Medalha, C. C., \& Mattioli, R. (1999). Natural preference of zebrafish (Danio rerio) for a dark environment. Brazilian Journal of Medical and Biological Research, 32(12), 1551-1553. https://doi. org/10.1590/S0100-879X1999001200016

Shams, S., Amlani, S., Buske, C., Chatterjee, D., \& Gerlai, R. (2018). Developmental social isolation affects adult behavior, social interaction, and dopamine metabolite levels in zebrafish. Developmental Psychobiology, 60(1), 43-56. https://doi.org/10.1002/dev.21581

Shen, Y.-B. (2008). Shrimps. In M.-M. Chang (Ed.), The Jehol fossils (pp. 52-57). San Diego, CA: Academic Press.

Shi, L., Yi, S., \& Li, Y. (2018). Genome survey sequencing of red swamp crayfish Procambarus clarkii. Molecular Biology Reports, 45(5), 799806. https://doi.org/10.1007/s11033-018-4219-3

Sinha, R. (2008). Chronic stress, drug use, and vulnerability to addiction. Annals of the New York Academy of Sciences, 1141, 105. https://doi. org/10.1196/annals.1441.030

Sneddon, L. U., Taylor, A. C., Huntingford, F. A., \& Watson, D. G. (2000). Agonistic behaviour and biogenic amines in shore crabs Carcinus maenas. Journal of Experimental Biology, 203(3), 537-545.

Soares, M. C., Cardoso, S. C., Carvalho, T. d. S., \& Maximino, C. (2018). Using model fish to study the biological mechanisms of cooperative behaviour: A future for translational research concerning social anxiety disorders? Progress in Neuro-Psychopharmacology and Biological Psychiatry, 82, 205-215. https://doi.org/10.1016/j.pnpbp.2017.11.014

Song, C., Liu, B.-P., Zhang, Y.-P., Peng, Z., Wang, J., Collier, A. D., ... Kalueff, A. V. (2018). Modeling consequences of prolonged strong unpredictable stress in zebrafish: Complex effects on behavior and physiology. Progress in Neuro-Psychopharmacology and Biological Psychiatry, 81(Suppl. C), 384-394. https://doi.org/10.1016/j.pnpbp. 2017.08.021

Souty-Grosset, C., Anastacio, P. M., Aquiloni, L., Banha, F., Choquer, J., Chucholl, C., \& Tricarico, E. (2016). The red swamp crayfish Procambarus clarkii in Europe: Impacts on aquatic ecosystems and human well-being. Limnologica, 58, 78-93. https://doi.org/10.1016/j.limno.2016.03.003

Spence, R., Fatema, M. K., Ellis, S., Ahmed, Z. F., \& Smith, C. (2007). Diet, growth and recruitment of wild zebrafish in Bangladesh. Journal of Fish Biology, 71(1), 304-309.

Spence, R., Fatema, M. K., Reichard, M., Huq, K. A., Wahab, M. A., Ahmed, Z. F., \& Smith, C. (2006). The distribution and habitat preferences of the zebrafish in Bangladesh. Journal of Fish Biology, 69(5), 1435-1448. https://doi.org/10.1111/j.1095-8649.2006.01206.x

Spence, R., Gerlach, G., Lawrence, C., \& Smith, C. (2008). The behaviour and ecology of the zebrafish, Danio rerio. Biological Reviews, 83(1), 13-34. https://doi.org/10.1111/j.1469-185X.2007.00030.x

Steenbergen, P. J., Richardson, M. K., \& Champagne, D. L. (2011). Patterns of avoidance behaviours in the light/dark preference test in young juvenile zebrafish: A pharmacological study. Behavioural Brain Research, 222(1), 15-25. https://doi.org/10.1016/j.bbr.2011.03.025

Stein, R. A. (1977). Selective predation, optimal foraging, and the predator-prey interaction between fish and crayfish. Ecology, 58(6), 12371253. https://doi.org/10.2307/1935078

Sterling, M. E., Karatayev, O., Chang, G. Q., Algava, D. B., \& Leibowitz, S. F. (2015). Model of voluntary ethanol intake in zebrafish: Effect 
on behavior and hypothalamic orexigenic peptides. Behavioural Brain Research, 278, 29-39. https://doi.org/10.1016/j.bbr.2014.09.024

Stewart, A. M., Braubach, O., Spitsbergen, J., Gerlai, R., \& Kalueff, A. V. (2014). Zebrafish models for translational neuroscience research: From tank to bedside. Trends in Neurosciences, 37(5), 264-278. https://doi.org/10.1016/j.tins.2014.02.011

Stewart, A. M., Cachat, J., Green, J., Gaikwad, S., Kyzar, E., Roth, A., ... Kalueff, A. V. (2013). Constructing the habituome for phenotypedriven zebrafish research. Behavioural Brain Research, 236, 110-117. https://doi.org/10.1016/j.bbr.2012.08.026

Stewart, A. M., Gaikwad, S., Kyzar, E., \& Kalueff, A. V. (2012). Understanding spatio-temporal strategies of adult zebrafish exploration in the open field test. Brain Research, 1451, 44-52. https://doi. org/10.1016/j.brainres.2012.02.064

Stewart, A., Riehl, R., Wong, K., Green, J., Cosgrove, J., Vollmer, K., ... Kalueff, A. V. (2011). Behavioral effects of MDMA ("Ecstasy") on adult zebrafish. Behavioural Pharmacology, 22(3), 275-280. https:// doi.org/10.1097/FBP.0b013e328345f758

Stewart, A. M., Ullmann, J. F. P., Norton, W. H. J., Parker, M. O., Brennan, C. H., Gerlai, R., \& Kalueff, A. V. (2015). Molecular psychiatry of zebrafish. Molecular Psychiatry, 20(1), 2. https://doi.org/10.1038/mp.2014.128

Stewart, A., Wu, N., Cachat, J., Hart, P., Gaikwad, S., Wong, K., ... Kalueff, A. V. (2011). Pharmacological modulation of anxiety-like phenotypes in adult zebrafish behavioral models. Progress in Neuro-Psychopharmacology and Biological Psychiatry, 35(6), 1421-1431. https://doi.org/10.1016/j. pnpbp.2010.11.035

Svoboda, J., Mrugała, A., Kozubíková-Balcarová, E., \& Petrusek, A. (2017). Hosts and transmission of the crayfish plague pathogen Aphanomyces astaci: A review. Journal of Fish Diseases, 40(1), 127-140.

Teles, M. C., \& Oliveira, R. F. (2016). Quantifying aggressive behavior in zebrafish. In K. Kawakami, E. E. Patton, \& M. Orger (Eds.), Zebrafish: Methods and protocols (pp. 293-305). New York, NY: Springer New York.

Theodoridi, A., Tsalafouta, A., \& Pavlidis, M. (2017). Acute exposure to fluoxetine alters aggressive behavior of zebrafish and expression of genes involved in serotonergic system regulation. Frontiers in Neuroscience, 11, 223. https://doi.org/10.3389/fnins.2017.00223

Tierney, A. J., Greenlaw, M. A., Dams-O'Connor, K., Aig, S. D., \& Perna, A. M. (2004). Behavioral effects of serotonin and serotonin agonists in two crayfish species, Procambarus clarkii and Orconectes rusticus. Comparative Biochemistry and Physiology Part A: Molecular \& Integrative Physiology, 139(4), 495-502. https://doi.org/10.1016/ j.cbpb.2004.10.010

Tierney, A. J., Kim, T., \& Abrams, R. (2003). Dopamine in crayfish and other crustaceans: Distribution in the central nervous system and physiological functions. Microscopy Research and Technique, 60(3), 325-335. https:// doi.org/10.1002/jemt.10271

Torres-Berrio, A., Cuesta, S., Lopez-Guzman, S., \& Nava-Mesa, M. O. (2018). Interaction between stress and addiction: Contributions from Latin-American. Neuroscience, 9(2639), 1-17. https://doi.org/10.3389/ fpsyg.2018.02639

Treves, F., \& Brown, M. (2000). Applied fish pharmacology. Kluwer Academic Publication, Aquaculture Series, 3, 309.

van der Staay, F. J. (2006). Animal models of behavioral dysfunctions: Basic concepts and classifications, and an evaluation strategy. Brain Research Reviews, 52(1), 131-159. https://doi.org/10.1016/j.brainresrev.2006.01.006

van der Staay, F. J., Nordquist, R. E., \& Arndt, S. S. (2017). Large farm animal models of human neurobehavioral and psychiatric disorders: Methodological and practical considerations. In P. Michael Conn (Ed.), Animal models for the study of human disease (pp. 71-100). Elsevier.

Varga, Z. K., Zsigmond, Á., Pejtsik, D., Varga, M., Demeter, K., Mikics, É., ... Aliczki, M. (2018). The swimming plus-maze test: A novel high-throughput model for assessment of anxiety-related behaviour in larval and juvenile zebrafish (Danio rerio). Scientific Reports, 8(1), 16590. https:// doi.org/10.1038/s41598-018-34989-1

Volgin, A. D., Yakovlev, O. A., Demin, K. A., Alekseeva, P. A., \& Kalueff, A. V. (2019). Acute behavioral effects of deliriant hallucinogens atropine and scopolamine in adult zebrafish. Behavioral Brain Research, 359, 274280. https://doi.org/10.1016/j.bbr.2018.10.033

Wallnau, L. B., \& Gallup, G. G. (1977). A serotonergic, midbrain-raphe model of tonic immobility. Biobehavioral Reviews, 1(1), 35-43. https:// doi.org/10.1016/0147-7552(77)90039-0

Walsh-Monteiro, A., Pessoa, R. D. S., Sanches, É. M., Carvalho, A. C. C. D., Silva, Y. C. D. B. E., Chirinéa, G., \& Gouveia, A. (2016). A new anxiety test for zebrafish: Plus maze with ramp. Psychology \& Neuroscience, 9(4), 457. https://doi.org/10.1037/pne0000067

Way, G. P., Ruhl, N., Snekser, J. L., Kiesel, A. L., \& McRobert, S. P. (2015). A comparison of methodologies to test aggression in zebrafish. Zebrafish, 12(2), 144-151. https://doi.org/10.1089/zeb.2014.1025

Wong, K., Stewart, A., Gilder, T., Wu, N., Frank, K., Gaikwad, S., ... Kalueff, A. V. (2010). Modeling seizure-related behavioral and endocrine phenotypes in adult zebrafish. Brain Research, 1348(Suppl. C), 209-215. https:// doi.org/10.1016/j.brainres.2010.06.012

Yamane, S., \& Takahata, M. (2002). Experimental modification of stepping course in spontaneously initiated locomotor behavior in the crayfish Procambarus clarkii Girard. Journal of Comparative Physiology A, 188(1), 13-23. https://doi.org/10.1007/s00359-001-0274-6

Zabegalov, K. N., Kolesnikova, T. O., Khatsko, S. L., Volgin, A. D., Yakovlev, O. A., Amstislavskaya, T. G., ... Kalueff, A. V. (2019). Understanding zebrafish aggressive behavior. Behavioural Processes, 158, 200-210. https:// doi.org/10.1016/j.beproc.2018.11.010

Zanandrea, R., Abreu, M. S., Piato, A., Barcellos, L. J. G., \& Giacomini, A. C. V. V. (2018). Lithium prevents scopolamine-induced memory impairment in zebrafish. Neuroscience Letters, 664, 34-37. https://doi. org/10.1016/j.neulet.2017.11.010

Zhang, Y., Raap, D. K., Garcia, F., Serres, F., Ma, Q., Battaglia, G., \& Van de Kar, L. D. (2000). Long-term fluoxetine produces behavioral anxiolytic effects without inhibiting neuroendocrine responses to conditioned stress in rats. Brain Research, 855(1), 58-66. https://doi.org/10.1016/ S0006-8993(99)02289-1

Zhdanova, I. V., Wang, S. Y., Leclair, O. U., \& Danilova, N. P. (2001). Melatonin promotes sleep-like state in zebrafish. Brain Research, 903(1-2), 263268. https://doi.org/10.1016/S0006-8993(01)02444-1

Zimmermann, F. F., Gaspary, K. V., Siebel, A. M., \& Bonan, C. D. (2016). Oxytocin reversed MK-801-induced social interaction and aggression deficits in zebrafish. Behavioural Brain Research, 311, 368-374. https://doi.org/10.1016/j.bbr.2016.05.059

\section{SUPPORTING INFORMATION}

Additional supporting information may be found online in the Supporting Information section.

Transparent Peer Review Report

How to cite this article: de Abreu MS, Maximino C, Banha F, et al. Emotional behavior in aquatic organisms? Lessons from crayfish and zebrafish. J Neuro Res. 2020;98:764-779. https://doi.org/10.1002/jnr.24550 